\title{
Illinois Walls: How Barring Indirect Purchaser Suits Facilitates Collusion*
}

\author{
Maarten Pieter Schinkel ${ }^{\dagger}$ Jan Tuinstra ${ }^{\ddagger}$ and Jakob Rüggeberg§
}

May 2005

\begin{abstract}
In its landmark ruling in Illinois Brick Co. v. Illinois, the U.S. Supreme Court restricted standing to sue for recovery of damages suffered from a breach of federal antitrust law to direct purchasers only. Even though typically antitrust injury is, at least in part, passed on to firms lower in the production chain and ultimately to consumers, Illinois Brick is binding precedent in a majority of states. In this paper, we draw attention to a strategic abuse of the rule as a shield against antitrust damages claims. We show that Illinois Brick facilitates upstream firms to engage horizontally in a collusive arrangement by focussing concealed vertical side-payments to discourage civil action on their direct purchasers only. Downstream firms are passed part of the upstream cartel profits through a symmetric rationing of their inputs at low prices. This 'Illinois Wall' arrangement sustains collusion in the production chain, substantially reducing total welfare. The more competitive the up- and downstream industries otherwise are, the more scope there is for the arrangement. Illinois Walls are shown to be resilient to entry, as well as to variations in the legal system. Several recent U.S. cartel cases display Illinois Wall symptoms.
\end{abstract}

JEL-codes: D4, L1, L4.

Keywords: Antitrust, treble private damages, Illinois Brick, tacit collusion, vertical restraints, rationing.

* We thank Frank Fisher, Joe Harrington, William Kovacic, Dan Kovenock, Robert Lande, Marco Lankhorst, Bob Larner, Margaret Levenstein, Frank Mathewson, Joe McCahery, William Page, Richard Posner, Chuck Thomas, Wouter Wils, participants at the 2004 IIOC meeting (Chicago) and the 2004 EARIE meeting (Berlin), as well as two anonymous referees for discussions, constructive suggestions and comments that helped us to improve substantially upon an earlier circulated version of this paper. Opinions and errors remain ours.

$\dagger$ Department of Economics and ACLE, Universiteit van Amsterdam. Corresponding author at: Roetersstraat 11, 1018WB Amsterdam, The Netherlands. E-mail: m.p.schinkel@uva.nl.

$\ddagger$ Department of Quantitative Economics and CeNDEF, Universiteit van Amsterdam. This research was partly conducted while visiting Universiteit Maastricht. Financial support from METEOR is gratefully acknowledged.

$\S \quad$ LECG, Madrid and Brussels. 


\section{Introduction}

Under section 4 of the Clayton Act, individuals or firms injured in their business or property by companies in breach of federal competition laws can claim treble damages in civil actions in order to be made whole. Since the production of goods or services typically involves a number of intermediate firms, any upstream anticompetitive behavior, such as price-fixing, is likely to spill-over into several markets, causing larger and smaller monetary injury in the production chain, before ultimately falling in part on the consumers. As a result, the precise break-down of such vertically spread antitrust damages is potentially complicated, involving applied general equilibrium analysis and sophisticated econometrics.

Twin Supreme Court rulings, the first in 1968 in Hanover Shoe Co. v. United Shoe Machinery Corp., the second in 1977 in Illinois Brick Co. v. Illinois, have significantly reduced the complexity of private punitive damages claims, however. ${ }^{1}$ In Hanover Shoe, the defendant, United Shoe Machinery Co.- which was earlier found to have monopolized the machinery market through long-term leasing contractsclaimed that the plaintiff, Hanover Shoe Co., a direct purchaser, was not injured by these anticompetitive contracts, because it had been able to pass the claimed overcharge on to its customers. The Supreme Court ruled against this defensive use of pass-on, finding that it would unduly lengthen and complicate antitrust cases and dissipate private incentives to seek antitrust injury recovery. As a result, irrespective of the question to what extent the direct purchaser indeed suffered damages, by Hanover Shoe it is entitled to recover three times the defendant's overcharge.

Several years later, the State of Illinois claimed in conjunction with several hundred local governmental institutions to have been harmed by a fixing of concrete block prices by the defendant, Illinois Brick Co., which artificially increased the costs of the contractors through which the plaintiffs carried out their construction contracts in a complex vertical chain. In its Illinois Brick decision, the Supreme Court also disallowed this offensive use of the pass-on argument, thus setting a companion standard to Hanover Shoe. The plaintiff was denied compensation and the precedent was set that only direct purchasers can successfully seek the recovery of damages from firms that breached federal antitrust laws.

In Illinois Brick, the main legal argument for denying indirect purchasers standing to sue is due to a multiple liability problem created by Hanover Shoe. Since the direct purchaser is entitled to the full overcharge by the latter standard, allowing indirect purchasers to sue for further money, as well, would effectively multiply the total liability of the defendant well over the three times total damages enunciated in the Clayton Act as the appropriate remedy. Illinois Brick thus repairs a liability problem Hanover Shoe created - albeit at the expense of possibly permitting unaffected parties to bring a damages claim, while denying parties that did suffer damages reparation.

Numerous scholars have, moreover, defended the pair of rules on economic grounds.

$1 \quad$ Cf. 392 U.S. 481 (1968) and 431 U.S. 720 (1977), respectively. 
In their March 1979 testimony to the Senate's Subcommittee on Antitrust and Monopoly, William Landes and Richard Posner took the view that the intent of Congress to allow for private damages claims in passing the Clayton Act was first and foremost to provide for an extra trust-deterrence by creating a private channel of policing, alongside public enforcement. ${ }^{2}$ They therefore emphasized efficiency rather than fairness of compensation as the appropriate criterion to judge Illinois Brick. Since direct purchasers typically have superior information on the effects of any anticompetitive acts of their suppliers, isolating monetary incentives with a small group of efficient detectors, rather than allowing for many fragmented indirect purchaser suits, is likely to enhance detection at significantly reduced legal transaction costs. Also, any costs involved in coordinating class action suits of parties damaged indirectly - and therefore each possibly only a little - are reduced with the incentive to file a private damages claim placed in a single hand. Moreover, the determination of all pass-ons of artificial cost increases would require courts to perform multiple, complicated and time-consuming analyses involving a large number of interested parties, which would be a social loss.

However, Illinois Brick has also been heavily disputed. To begin with, three Supreme Court judges dissented in the original decision. Also, in both the Senate and the House of Representatives bills were proposed, but never enacted, to overrule the two Supreme Court rulings. In their long argument, Robert Harris and Lawrence Sullivan maintained that pass-on calculations are not sufficiently complex and costly to justify denying indirect parties their right to be made whole. ${ }^{3}$ A number of further developments in jurisprudence have somewhat softened the strict restriction on indirect purchasers' standing to sue. Since the 1981 Supreme Court decision in J. Truett Payne Co., Inc. v. Chrysler Motors Corp., parties that only dealt with the cartel members indirectly can nevertheless ask in a civil action for injunctions to break up the upstream cartel in state courts. ${ }^{4}$ Also, in its 1989 decision in California v. ARC America Corp., the Supreme Court left it to the discretion of individual states whether or not to allow indirect purchaser suits. ${ }^{5}$ As a result, limitations on who has standing to sue in private antitrust damages cases today vary from state to state - with states allowing indirect purchasers to claim antitrust damages being referred to as 'Illinois Brick repealers'. ${ }^{6}$ Whilst a substantial number of states have since repealed fully or in part, Hanover Shoe and Illinois Brick nevertheless continue to stand as binding legal constraints in many important antitrust damages cases. ${ }^{7}$

\footnotetext{
2 Landes and Posner (1979). See also Lopatka and Page (2004) and the references therein.

3 Harris and Sullivan (1979). For a critical reply to Harris and Sullivan (1979), see Landes and Posner (1980).

$4 \quad$ Cf. 451 U.S. 557 (1981).

Cf. 490 U.S. 93 (1989).

Cf. Davis (1997), Page (1999) and Hovenkamp (1999).

7 In December 1998, for example, in Alex Campos, et al., Petitioners v. Ticketmaster Corporation, No. 98-127, the Supreme Court reestablished that the petitioners were rightfully barred by the Court of Appeals from recovery of damages by the defendants appeal to Illinois Brick. Also,
} 
Opposition remains strong, but is essentially based on fairness objections and the assessment that legal transaction costs are not prohibitively large. ${ }^{8}$

In this paper, we draw attention to a detrimental efficiency effect of this state of affairs which, we believe, should be weighed against the set of rules' potential to increase private incentives to bring anticompetitive practices to light and reduce the costs of legal procedures. By effectively shielding antitrust violators from all private parties but those directly involved, we argue, Illinois Brick may potentially give upstream firms a safe-haven to engage in collusive arrangements, as long as they can discourage their direct purchasers - and them only - from filing suit. Thus allowing potential violators to focus discouragement efforts on the sole party with standing to sue may neutralize part of the purported enhanced private incentive effect Illinois Brick.

Suggestions to this effect have been made in passing in the early literature. Harris and Sullivan (1979) remark that a restriction of standing to sue to the direct purchasers may effectively foreclose private suits to the extent that the ongoing relationship between the potential defendant and the direct purchasers has value to the latter. $^{9}$ The authors were satisfied, however, that judicial experience showed that cases nevertheless were brought by direct purchasers. In Snyder (1986), the possibility of direct purchasers fearing "retaliation" by their suppliers, on which they may depend, is noted yet similarly dismissed. ${ }^{10}$ The idea found little acclaim in the extensive literature on Illinois Brick and private antitrust damages cases. To our knowledge, it never inspired a thorough analysis.

An early concern has been whether the increased incentive effect for direct purchasers would be sufficiently strong to outweigh the reduction in cases that before were brought by indirect purchasers. The question inspired several empirical analyses that quite consistently found an increase in the total number of private antitrust damages cases after Hanover Shoe in 1968, yet a more than off-setting decrease after Illinois Brick in 1977. Landes and Posner (1979) already report a structural reduction from 1977 to 1978 - that is, immediately after Illinois Brick -in the total number of private cases brought in various districts. The authors hesitated, however, to conclude from this that Illinois Brick led to more than a correction of the Hanover Shoe increase. Instead, they conjectured that the fall in private damages actions reflected an overall downward trend in public enforcement from 1977 to 1978, noting that pri-

Microsoft escaped private damages in several states (while settling for billions of dollars in others) by appealing successfully to Illinois Brick-cf. Davidson v. Microsoft Corp., No. 60, 2/28/02 and "Indirect Purchasers Barred From Bringing Claim Against Microsoft Under State Statute," Electronic Commerce $\mathcal{E}_{3}$ Law Report, Volume 7, Number 11 of Wednesday, March 13, 2002.

$8 C f$. Hovenkamp (1999), Section 16.6, or the stand on Illinois Brick of the American Antitrust Institute at www.antitrustinstitute.org.

9 Cf. op. cit., pp. 351-2. Similar concerns were forwarded by some of the proponents of bills to overrule Hanover Shoe and Illinois Brick. Cf. Sneeden (1979), p.219.

10 Op. cit., p.470n. 
vate claims often follow up on adverse findings in public actions. ${ }^{11}$ But again later studies, involving more post-ruling data, in Snyder (1986) and Joyce and McGuckin (1986), found more than a reversal after Illinois Brick of the increase in the number of private cases since Hanover Shoe, suggesting a permanent negative effect of the pair. Still, however, the authors would not conclude that the effects could be due to the Supreme Court constraints to private litigation - as the over-all decrease in the number of private cases found was small and statistically insignificant. Instead, the net effect of Hanover Shoe and Illinois Brick was interpreted to be "neutral". ${ }^{12}$

One reason perhaps for why the few initial observations that Illinois Brick could discourage private antitrust damages actions were so easily discarded may have been that the long-term relationships at stake in the chain were perceived merely as issues of "continuity and goodwill," as Harris and Sullivan (1979) referred to them. They were, that is, not understood to actively involve the suppliers. It is, indeed, questionable that direct purchasers would value such weak ties sufficiently to keep them from exercising their right to obtain treble the overcharge - which is typically a lot of money. Still this is likely to be true when switching from one supplier to another involves non-negligible costs, such as in the relationship with a software company responsible for a company's main management information systems, or that with the external accounting office. Even though filing a claim against such vital suppliers would certainly put stress on the service relationship, probably leading to embroilment and a discontinuing of trade, the costs involved in overcoming these exogenous market imperfections probably do not amount to the many millions of compensation typically at stake in antitrust damages cases. Moreover, true retaliation would often itself be a violation of law, offering independent possibilities to seek justice.

A much more serious cost to consider by downstream firms before filing a complaint, however, would be any specific benefits actively forwarded by the suppliers to the direct purchasers as part of their collusive arrangement. Schemes, in other words, through which downstream retailers benefit in intricate ways from the presence of the upstream cartel, and that would stop if the cartel were to be sued in court. Claims that vertically passed-on cartel benefits are indeed a reality have been made in the more recent literature. ${ }^{13}$ In the context of Illinois Brick, such downstream benefits could be interpreted as a stick-and-carrot to keep the direct purchasers from exercising their unique right to recover private damages. When such side-payments from the anticompetitive upstream industry to their downstream purchasers, made in exchange for not filing suit, are at stake, then one can speak of 'retaliation' against filing a private antitrust damages claim. The side-payments would in that case be withdrawn, as the civil actions would lead to the breakdown of the upstream collusive arrangement - that is the source of the money. This kind of long-term relationship is

\footnotetext{
11 Op.cit., pp.632-4.

12 Snyder (1986), p.482; Joyce and McGuckin (1986), p.239.

13 See Levenstein and Suslow (2004) and some of the references there cited. The issue is further discussed in Section 6 below.
} 
all the more interesting, not only because it is likely to provide a substantially larger incentive for the direct purchasers, but also because it is costly for the suppliers to maintain. An interesting question to ask, therefore, is whether such upstreamdownstream collusive agreements are tacitly sustainable, and what role Illinois Brick can have in setting them up.

In the following, we consider circumstances in which firms may use Illinois Brick to raise an 'Illinois Wall' between themselves and their indirect customers further down in the chain, so as to shield themselves from private damages claims - and hence detection - through private enforcement. In a model of a vertical production chain, there is a variable number of firms in competition in an upstream industry (also referred to as 'wholesalers') that sell their products as inputs to a competitive group of direct purchaser downstream industry ('retailers'), which in turn sell their output directly to the final consumers. Up- and downstream firms have repeated interaction over an infinite period of time, which captures the long-term nature of their trade relationship. The upstream industry may seek to collude and fix prices. If it does so, it can, by appealing to Illinois Brick, concentrate its efforts to keep those affected by its anticompetitively high prices from filing a treble damages claim solely on the retailers. With them it needs to work out an attractive compensation scheme, which is covert and leaves no obvious evidence of retail involvement. If it would, antitrust suits could potentially be brought by the consumers, then the direct purchasers of an upstream-downstream-cartel. The two industries manage to do this using a simple rationing scheme. By symmetrically selling to each of the downstream firms only a limited amount of inputs at a low input price, the upstream cartel creates an artificial scarcity on the market for final consumer products that is beneficial to the downstream firms. This tacit vertical understanding between the industries creates consumer detriment, yet escapes prosecution. And because of that, so does the upstream cartel, even if the whole upstream-downstream collusive arrangement would be common knowledge.

The potential perverse effect of Illinois Brick we point out is just one aspect of a more extensive treatment of incentives effects from private damages claims and their contribution to efficiency that includes Salop and White (1986), Salant (1987), Baker (1988), Besanko and Spulber (1990), Briggs, Huryn and McBride (1996) and Harrington (2004a). The seminal Salop and White (1986) surveys aspects and empirics of private antitrust enforcement - in which Illinois Brick is only briefly mentioned as a desirable 'trimming of the plaintiffs' powers and strengthening the defendants' powers" (op. cit., p.1039). Baker (1988) and Besanko and Spulber (1990) in essence extend the position of Landes and Posner (1979) that private antitrust enforcement provides a more direct, and therefore better informed channel, thus enhancing legal efficiency. These papers focus on asymmetric information, arguing that in the presence thereof, private claims increase efficiency and should therefore be encouraged, in particular through sufficiently high damages multiples. Salant (1987) shows instead that increasing the damages multiple may raise the market price when firms incorpo- 
rate the threat of private penalties in their objective functions. Also in Briggs, Huryn and McBride (1996), in which the interplay between public cases and private followup suits is considered, a potential inefficiency of the trebling of damages is pointed out. As defendants invite parties to bring follow-on treble damages cases by signalling a weak position when they settle in the public case, inefficiently many public cases are brought in equilibrium, that moreover are battled over long in court, whereas settlements would otherwise have been efficient. In Harrington (2004a) it is shown how participants of past cartels that have since fallen apart may still non-cooperatively sell at prices higher than competitive levels, knowing that a low post-cartel price level will serve as a base for large private antitrust damages estimates. The possibility that Illinois Brick may deter private damages claims and facilitate collusion, however, is not considered in this literature.

The remainder of this paper is organized as follows. In the next section, industry relations and the competitive benchmark are modelled in a repeated game setting. Section 3 considers upstream collusion and the damage it does. It is established that when standing to sue for private damages is unrestricted, collusion is always deterred. Section 4 presents our 'Illinois Wall'. It is shown that, when downstream firms are sufficiently patient, the arrangement shields the upstream industry from antitrust damages claims, thus generically facilitating collusion. In Section 5, the Illinois Wall is shown to be detrimental and robust. In particular, it is shown how the more competitive both the up- and the downstream sector initially are, the more scope there is for the strategic abuse of Illinois Brick. Section 6 discusses various symptoms of the effect in recent U.S. cartel cases, including Lysine and De Beers, which may indicate that Illinois Walls are indeed a reality. Section 7 concludes. Proofs of the results are offered in an appendix.

\section{Upstream-Downstream Competition}

Consider a market in which $n$ upstream firms, indexed $i=1,2, \ldots, n$, each produce a differentiated good against constant marginal costs $c$ that, without loss of generality, are normalized to be equal to zero, and no fixed costs. Each upstream firm has a unique relationship with one of the (consequently $n$ ) downstream retailers, in which it sells an amount $q_{i}$ of its wholesale product at a price $p_{i}$. Each retailer prepares its wholesale inputs for retail in a linear production process that, for simplicity, is assumed to involve no further costs, in order to produce its final consumer commodity, of which it subsequently sells an amount $Q_{i}$ at price $P_{i}$. There are no capacity constraints. Consumer demand for variety $i$ is given by the demand function

$$
Q_{i}\left(P_{1}, \ldots, P_{n}\right)=\frac{(1-e)\left(1-P_{i}\right)-e \sum_{j \neq i}\left(P_{i}-P_{j}\right)}{(1+(n-1) e)(1-e)},
$$

where $e \in[0,1)$ is a measure of the (symmetric) product differentiation between the varieties, ranging from distinct monopolized markets $(e=0)$ to competition between 
next to fully homogeneous commodities (e close to 1$).{ }^{14}$ The organization of the market is sketched in Figure $1 .^{15}$

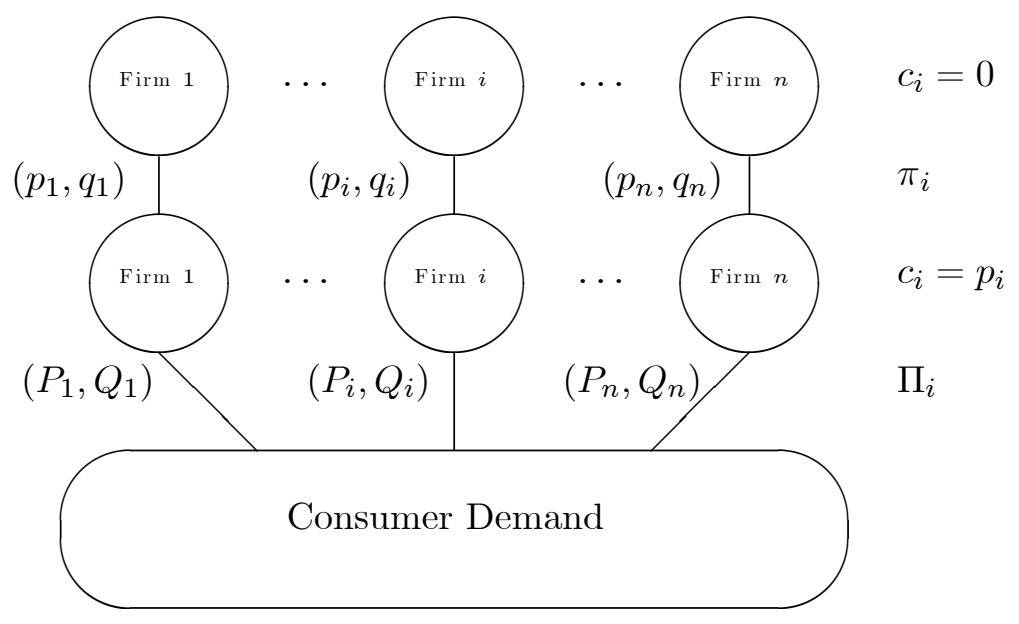

Figure 1: Differentiated goods marketed in competing parallel vertical production chains.

Retailers and wholesalers compete on prices in a Bertrand fashion. Furthermore, it is assumed that the market exists indefinitely, without technological progress changing its supply structure, nor demographic or other changes shifting demand. As a result, the up- and downstream firms are engaged in a long-term relationship. In their strategic planning, firms all take an infinite time horizon as a basis, in which they discount future profits at a common quarterly rate $\delta \in[0,1)$. Market interaction can therefore be understood as Bertrand competition in a repeated game framework. When both industries act non-cooperatively, the one-shot Bertrand equilibrium is played in each period. Since the wholesalers control the inputs of the retailers, this is a sequential game, of which the subgame perfect equilibrium is found by backward induction, as follows.

14 This specific way of capturing product differentiation in a linear demand function was originally proposed in Bowley (1924). It is used extensively in the modern literature-e.g. in Vives (1999) and Harrington (2004b) - and based on utility maximization by a representative consumer with a taste for variety, as specified in Appendix A.1.

15 The analysis in this paper is restricted to a market structure with competing vertical chains that have exclusive single-product dealing arrangements. It may alternatively be that each upstream firm deals with more than one downstream firm. Likewise, competition may be stronger at the upstream level, for example with wholesalers that all sell the same homogenous input, which the downstream firms use to produce differentiated consumer goods. The market structure we analyse in the paper is analytically most transparent. Moreover, as discussed in Section 5, when an Illinois Wall exists in the present model, it always exists in these more competitive market structures. 
For given upstream wholesale prices $\left(p_{1}, \ldots, p_{n}\right)$, the downstream Bertrand-Nash equilibrium prices are

$$
P_{i}=A_{e, n}^{\prime}\left(B_{e, n}^{\prime}+C_{e, n}^{\prime} p_{i}+D_{e, n}^{\prime} \sum_{j \neq i} p_{j}\right),
$$

in which $A_{e, n}^{\prime}, B_{e, n}^{\prime}, C_{e, n}^{\prime}$ and $D_{e, n}^{\prime}$ are positive parameters, the value of which depend on $n$ and $e .{ }^{16}$ From this the implied demand for upstream firm $i$ follows as

$$
q_{i}\left(p_{1}, \ldots, p_{n}\right)=A_{e, n}-B_{e, n} p_{i}+C_{e, n} \sum_{j \neq i} p_{j}
$$

in which $A_{e, n}, B_{e, n}$ and $C_{e, n}$ are related positive constants.

Each upstream firm $i$ subsequently chooses $p_{i}$, given $p_{1}, \ldots, p_{i-1}, p_{i+1}, \ldots, p_{n}$ by maximizing profits based on the implied demand equation (3). The resulting set of best-reply functions determines the Bertrand-Nash equilibrium wholesale prices. Since product differentiation in the demand structure is symmetric, it suffices to consider symmetric Nash equilibria only, so that all wholesale and all retail prices are the same. Let this common upstream equilibrium wholesale price be $p^{c}$, and the downstream equilibrium retail prices be $P^{c}$ - where the superscript ' $c$ ' refers to this being the competitive benchmark case.

With all prices known, similarly equal equilibrium upstream sales $q^{c}$ and downstream sales $Q^{c}$ follow. The resulting profits are, in accordance with prices and quantities, indicated by lower case $\pi^{c}$ for an upstream firm and upper-case $\Pi^{c}$ for each firm downstream. Notice that due to the one-to-one production technology used in the conversion of wholesale bulk into retail sales, the up- and downstream quantities traded in equilibrium are equal. That is, $q^{c}=Q^{c}$.

\section{Upstream Collusion and Damages Claims}

Suppose now that the upstream industry conspires to fix the wholesale prices charged to the downstream retailers. Suppose the cartel is able to ensure internal stability. ${ }^{17}$ Let the downstream industry remain competitive. The upstream cartel will then be able to act as a monopolist on the demand function (3) and, in order to maximize cartel profits, it sets the prices of all products equal to one half, i.e., $p^{a}=\frac{1}{2}$-where

\footnotetext{
16 A complete characterization of the Bertrand-Nash equilibrium is given in Appendix A.2.

17 In the following, the focus is on the stability of vertical collusive arrangements between the up- and downstream industries. Horizontal cartel stability can be guaranteed under reference to the traditional cartel stability arguments - primarily punishment strategies as introduced in Friedman (1971). In addition, note that the possibility to erect an Illinois Wall allows for the upstream cartel to coordinate using quite explicit arrangements - which arguably makes it more easy to reach agreement than purely tacit means would. The issue is taken up again in Section 5.
} 
the superscript ' $a$ ' refers to the fact that the upstream firms now engage in 'anticompetitive behavior'. Let the resulting equilibrium sales be denoted by $Q^{a}=q^{a}$, with profits for an individual upstream firm denoted by $\pi^{a}$, and individual downstream firm's profits under the upstream collusive scheme denoted by $\Pi^{a} .^{18}$

Colluding in this manner is obviously profitable for the wholesalers. The retailers, however, are hurt by the upstream cartel. Since their products are imperfect substitutes, the retailers price above marginal costs in equilibrium, so that they do not pass the entire increase in input prices on to the consumers. Hence, they will see their profits decrease as a result of the increased wholesale prices. Also, since demand is elastic, by the same argument the increased retail prices cause consumer detriment. Should, therefore, the wholesalers pursue their intentions to collude, in principle each individual downstream firm and each consumer would have an incentive to seek reparation of the damages sustained from this anticompetitive act. To file a successful private antitrust damages claim requires that plaintiffs can prove that the upstream firms breached the federal antitrust laws. Suppose in the following that sufficient evidence to bring an admissible antitrust injury claim against the upstream cartel is available to all parties hurt by its conspiracy to restrict trade.

Exactly what should serve as a basis for determining the damages that a successful claimant is entitled to is a matter of dispute - in court, as well as in the literature. It is customary in U.S. antitrust law to calculate the damages suffered from anticompetitive behavior as the so-called 'overcharge'. It is computed as the difference between the anticompetitively raised price and the price that would have prevailed without the anticompetitive acts - sometimes referred to as the 'but for' price - multiplied by the quantity purchased by the claimant under the anticompetitive regime. By thus neglecting the elasticity of demand, the overcharge underestimates the lost profits downstream, for it ignores profits that would have been made on the greater volume. A similar dead-weight loss reduction of consumer surplus is also not accounted for in this method. 19

If the breach inflicted injury for longer periods of time, the overcharge is based on total sales over the period in which the anticompetitive prices were being charged. Plaintiffs are, however, not allowed to include lost compounded interest over damages sustained in the past. ${ }^{20}$ Moreover, the Clayton Act includes a statute of limitations which requires civil actions to be filed within a four year period. Cases filed after

\footnotetext{
18 See Appendix A.3 for explicit solutions.

19 Lovell (1982) concludes that treble damages are actually double damages on the argument that the dead-weight loss is half the monopoly profit when demand is linear and average cost constant. A more precise determination of damages, or to whom they should accrue, is typically not the objective of the Court. Argumentation based on demand substitution is usually not entered, or only mentioned in passing by the plaintiffs to show their damage estimates are conservative. We thank Frank Fisher for these insights. See also Page (1996).

20 That is, no pre-judgement interest is awarded on the claim. If, however, the alleged anticompetitive acts continued after the case was filed, and they are indeed found to be anticompetitive, interest does accumulate from the filing date onwards. Cf. Lande (1993).
} 
this period are in principle not admissible so that no damages can be awarded, even when the anticompetitively raised prices remained by subsequent "routine" following of the dated cartel agreement. The statute of limitations need not apply when the antitrust violation was "fraudulently concealed." In practise, however, the cases are often difficult to prove. ${ }^{21}$ Also, the statute can be tolled in government proceedings, and in several high-profile per se offences, including price-fixing, it was indeed put aside and damages were awarded for longer periods. ${ }^{22}$ On the other hand, given such issues as the absence of pre-judgement interest, the probability of preclusion by reason of lapse of time, the possibility of an out-of-court settlement, and increasing difficulty to document back claims due to the deterioration of evidence, so that it becomes increasingly burdensome to prove in court that damages incurred in the distant past ought to be awarded, it is reasonable to assume that an accumulating damages claim depreciates. ${ }^{23}$ In fact, balancing all these arguments, Lande (1993) argues that in practice damages awards are on the order of single damages, rather than treble. We need in the following only that any successful recovery claim is bounded.

Let the one-period total overcharge suffered by a downstream firm as a function of an anticompetitively increased input price $p$ and the quantity $q$ purchased at that price be defined as

$$
D(p, q)=\left(p-p^{c}\right) q
$$

Also, let the per period nominal damages multiple be $\mu$. Assume that, for the reasons discussed above, indeed the accumulating damages stock depreciates by a factor $\beta \in[0,1)$. As a result, from the starting date of the cartel agreement onwards, as long as the cartel prices remain, damages accumulate digressively. Let $\mathbf{D}_{t}$ be thus accumulated damages at period $t$, so that

$$
\mathbf{D}_{t+1}=\beta \mathbf{D}_{t}+\mu D(p, q)
$$

Suppose that the date from which damages can be calculated is $\tau$-where $\tau$ could be equal to the starting date of the cartel, $T_{0}$, or it could be equal to $T+1-T^{s}$, where $T^{s} \geq 1$ is the number of periods for which damages can effectively be claimed before the statute of limitations applies. Note that if the statute of limitations does not apply in a given case, $T^{s} \rightarrow \infty$. The state variable $\mathbf{D}_{t}$ then develops over time

\footnotetext{
21 Generally, for example, silence by the defendant is not enough, as it requires explicit acts such as stating false prices on bills, or writing false statements, to show fraud. Cf. Lande (1993).

22 In the VISA Check/MasterMoney antitrust litigation, No. CV-96-5238, for example, brought March 17, 1999 (and eventually settled in 2003 for $\$ 3.05$ billion) although it was recognized that the damages were, in fact, sustained since the anticompetitive introduction of Visa and MasterCard's debit cards in 1975 and 1981 respectively, the plaintiff class was limited to recovering those damages suffered from the period October 261992 to the date of judgement. See http://www.inrevisacheckmastermoneyantitrustlitigation.com.

23 Cf. Harrington (2004b), on which our modelling of depreciating accumulating damages in the following is based.
} 
into a damages claim total, up to and including time $T$, which is equal to

$$
\mathbf{D}_{T}=\sum_{t=\tau}^{T} \beta^{T-t} \mu D(p, q) .
$$

Each downstream firm would potentially be entitled to this amount of money.

Likewise, the class of consumers - provided it has standing to sue can claim damages from this cartel to the value of

$$
\boldsymbol{\Delta}_{T}=\sum_{t=\tau}^{T} \beta^{T-t} \mu\left(P-P^{c}\right) Q
$$

per product variety, where $P$ is the final goods price asked in equilibrium by the competitive layer of downstream retailers, which all face the anticompetitively raised wholesale price. $Q$ is their corresponding output.

In line with discounted back-damages, we abstract in the following from any further legal transaction costs. If a private antitrust damages suit with merit is brought for the real damages multiple, it is assumed there will be no further difficulty in substantiating the claim, so that it will lead with certainty to a granting of the determined damages money. Also, any legal costs involved in bringing an individual claim are assumed to be negligible. It may be, for example, that the downstream firms share their legal costs, as only one initial court case, brought by a single downstream firm or as a class action, would in principle suffice for all downstream firms to claim their individual damages at little incremental costs in follow-on suits. Henceforth, we will assume therefore that when one individual downstream firm files suit, all others will follow and the upstream industry will be ordained to pay damages based on the industry wide overcharge. Consumer also handle their claims collectively in a class. Finally, in order to isolate the documented effect that private damages claims are essential in bringing anticompetitive behavior to light, we abstract until Section 5 from the possibility that any other cases, such as shareholder suits or public criminal actions, are brought against the upstream cartel. In these circumstances, we have the following benchmark result.

Proposition 1 There exists a critical per period nominal damage multiple $\mu^{*} \in$ $\left[\frac{1}{2}, \frac{2}{3}\right]$ such that, as long as $\mu \geq \mu^{*}$ and both downstream firms and consumers have standing to sue for reparation of their antitrust damages, any upstream cartel will be deterred.

The result is not trivial. The reason for this is a potential perverse effect created by the overcharge calculus practice. Since parties can file claims for determined amounts of money, irrespective of the extent of their actual injury, they may in fact, when the available multiple damages surpass the true hurt, be encouraged to postpone notifying the arrangement and accumulate a future damages claim instead. 
In particular, this may be tempting for the downstream firms, which are able to pass part of the overcharge on to the consumers, so that they may be damaged really only very little. But even for the consumers, who certainly share in the burden, the possibility of later being awarded several times the overcharge, which may be more than the true injury, may sustain collusive agreements that have over-all detrimental welfare effects for longer periods of time, even when all involved are aware of the cartel and the damage it does. In Brina (1983) — which discusses the misuse of the statute by firms in breach of federal competition laws seeking to escape damages claims - it is explained how the original rationale for the statute was to prevent such a 'wait and see' attitude towards slumbering anticompetitive arrangements. Our result shows that when back-damages are bounded by the four years statutory limit or depreciate, a limit is put to such postponements for less than single nominal damages.

\section{An Illinois Wall}

When all parties have standing to sue, the private antitrust enforcement channel alone would generally install sufficient incentive to discipline the upstream industry into behaving competitively, even when less than single nominal damages are awarded. Hence, collusion is likely to be deterred by the threat of antitrust damages claims, unless the upstream cartel can somehow ward them off. Here is where the potential anticompetitive abuse of Illinois Brick comes into play. One way to avoid damages claims, namely, would be to pay those with standing to sue a sufficiently high compensation for the loss they incur when they refrain from exercising their right to claim damages. By giving only the direct purchasers standing to sue for antitrust damages, Illinois Brick allows the upstream cartel to focus any such bribing efforts solely on the downstream industry. Even if consumers would know about the existence of the upstream cartel, that is, they would be barred from bringing a claim against it, for they only deal indirectly with those in breach of competition law. If side-payment were not so focussed by law, they would not generally be possible, since the cartel can typically only profit from its collusive arrangement at the expense of total welfare. ${ }^{24}$ Illinois Brick may thus create a safe-haven for upstream collusion by allowing to build an 'Illinois Wall' between the cartel and indirect purchasers further down in the chain.

It is not obvious, however, that a side-payment scheme to buy the silence of each downstream firm exists. The key is that the upstream cartel compensates the downstream firms for their true injury plus the amount of treble overcharge they are entitled to irrespectively by Hanover Shoe. Also, while one can think of several ways in which

\footnotetext{
24 Under certain conditions, when competition is little to begin with, combined horizontal and vertical collusive arrangements can, in fact, enhance total welfare, as they (partly) eliminate double marginalization in the chain. The issue is discussed below the theorem in the text. Regions for which it applies in our model, and a subtle relationship to our Illinois Wall arrangement, are identified in Section 5 .
} 
the upstream firms can indeed pass on some of their cartel profits to compensate their direct purchasers - ranging from overt money transfers to offering CEO's all-inclusive jaunts to the Tropics - any scheme to complement Illinois Brick has to satisfy several constraints. It should be sufficiently interesting for the downstream firms to accept the arrangement. This implies, among other things, that no retailer has an incentive to benefit from the side-payments first, and then file suit after all. Also, the involvement of the downstream firms should not leave evidence to the consumers - or other indirect purchasers. If it would, these next-in-line indirect purchaser would be the direct purchasers of an identifiable cluster of up- and downstream firms in breach of antitrust law and thus have standing to sue for treble damages against the full chain. Furthermore, the arrangement has to be simple enough for all parties involved to understand its value with little or no communication.

One possible compensation scheme that satisfies these constraints amounts to a restriction on the number of wholesale inputs the upstream cartel sells to their downstream retailers. This creates an artificial scarcity on the downstream market, from which the downstream firms benefit. Particularly this is so if the cartel distributes limited amounts of goods evenly over the various downstream retailers, and charges relatively low prices per unit. When the downstream firms are "put on allocation at low input prices' in this way, it has an effect that is illustrated in Figure 2.

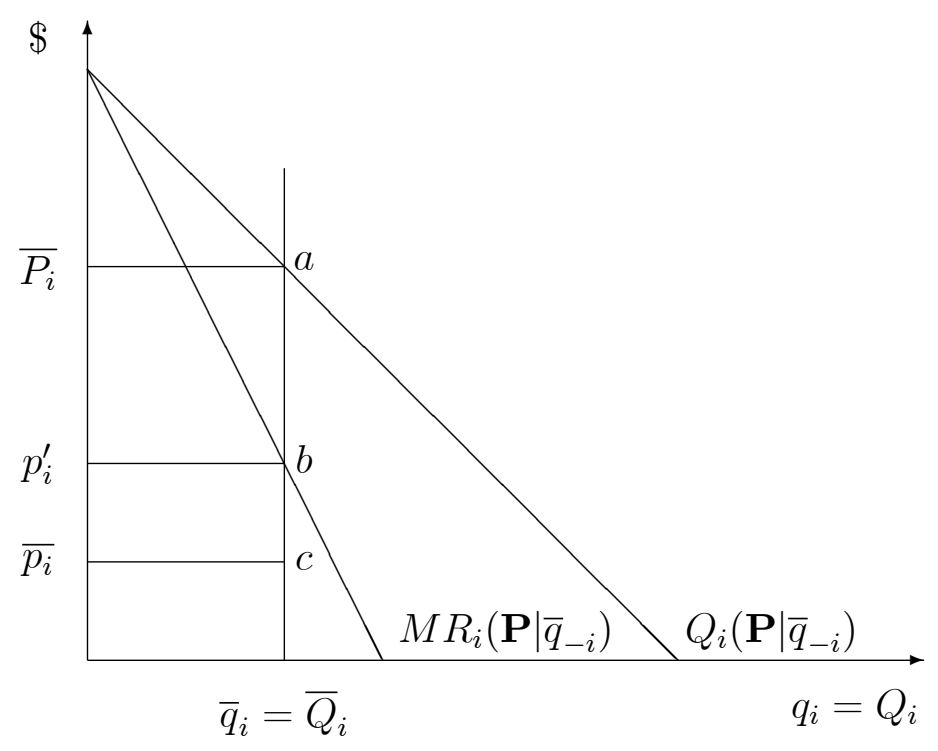

Figure 2: An individual downstream retailer 'put on allocation at low input prices'.

The figure displays the individual situation of a downstream firm that is horizontally in Bertrand competition with the varieties offered by the other retailers. The upstream cartel supplies the downstream firm with a restricted quantity of inputs 
$\bar{q}_{i}$ only, at an input price per unit of $\bar{p}_{i}$. Given its linear production technologyinvolving no further costs by assumption - and in the knowledge that all other downstream firms have been allotted a similarly restricted number of inputs and therefore each have limited supply as well, each downstream firm can safely expect to sell its $\bar{q}_{i}=\bar{Q}_{i}$ units at a consumer market price of $\bar{P}_{i}$. That is, in equilibrium, each downstream firm faces a residual demand curve plotted as $Q_{i}\left(\mathbf{P} \mid \bar{q}_{-i},\right)$, in which $\mathbf{P}$ is short for $\left(P_{1}, \ldots, P_{n}\right)$ and $\bar{q}_{-i}$ refers to $\left(\bar{q}_{1}, \ldots, \bar{q}_{i-1}, \bar{q}_{i+1}, \ldots, \bar{q}_{n}\right)$, so that the individual downstream profits under this rationing scheme are represented by area $\bar{P}_{i} a c \overline{p_{i}}$.

Given equilibrium residual demand, the input price that would have corresponded to this sales price of $\bar{P}_{i}$, if it were not for the upstream cartel artificially rationing the input levels, is $p_{i}^{\prime}$, with an associated profit of $\bar{P}_{i} a b p_{i}^{\prime}$. Hence, the quantityconstraint-low-input-price combination increases the profits of the downstream firm by an amount represented by $p_{i}^{\prime} b c \bar{p}_{i}$. This extra profit can be understood as compensation for the downstream producer awarded by the upstream firms. If the direct purchasers do understand the rationing at low prices in this way, the arrangement can act to silence the sole party with an incentive and the power to speak up and unmask the anticompetitive arrangement. No money passes hands. The deal is tacit, simple, and thus covert. It requires little or no communication and therefore need not leave any evidence so that it can escape prosecution under the antitrust laws by consumers - other indirect purchasers or government authorities, for that matter, should they be more alert. After all, the upstream firms can hardly be forced by law to supply more inputs than the downstream firms claim they are willing to buy.

The arrangement allows for a stable Illinois Wall, as follows. Suppose that the upstream cartel puts the downstream retailers symmetrically on allocation by choosing a single reduced price-quantity combination $(\bar{p}, \bar{q})$ for each variety. In light of this, each downstream firm determines its pricing decision as follows.

$$
\begin{aligned}
& \max _{P_{i}}\left(P_{i}-\bar{p}\right) Q_{i}\left(P_{1}, \ldots, P_{n}\right) \\
& \text { s.t. } Q_{i}\left(P_{1}, \ldots, P_{n}\right) \leq \bar{Q}=\bar{q},
\end{aligned}
$$

where the latter equality follows from the one-to-one production technology. In the symmetric Bertrand-Nash equilibrium, this results in equal output prices $\bar{P}$ that clear the market for each variety. Note that setting input levels as well as input prices effectively gives the wholesalers' cartel control over its retailers' consumer market behavior. This partly integrates the objective functions in the vertical chains, reducing the problem of double marginalization that otherwise exists for the wholesalers. The integration is not perfect, however, as the cartel's choices are constrained by the fact that the side-payments required for silence are passed on using these very same instruments. The explicit solution to (5) is given in Lemma 7 in Appendix A.4. ${ }^{25}$

25 It is not obvious that each retailer indeed sets its downstream sales $Q_{i}$ equal to the maximum capacity $\bar{Q}$ offered by the upstream cartel. The reason for this is that, given $(\bar{p}, \bar{q})$, each downstream 
Knowing this best-reply equilibrium play of the downstream retailers, the upstream cartel can design a rationing scheme that maximizes profits, whilst obeying the restriction that none of the retailers has an incentive to bring a private damages claim. This is equivalent to a trigger strategy, in which the upstream cartel rations at a low price as long as no firm in the downstream industry sues. If any of the downstream firms decides to bring a private damages claim, the upstream cartel unravels and the industry reverts to Bertrand competition. Enforced by competition authorities and courts, this cartel breakdown is a credible threat to a retailer that considers to sue.

Faced with this situation, the (symmetric) profits of each individual downstream firm when refraining from suing and accepting the side-payments instead are at current time $T$ - equal to

$$
\sum_{t=T}^{\infty} \delta^{t} \bar{\Pi}(\bar{p}, \bar{q})
$$

If a downstream firm would opt to bring a private treble damages suit, we assume that it receives the lucrative bribe for the period in which it defects from the tacit arrangement, plus multiple damages - which, in line with the model efficiency of the legal system, we assume for simplicity to be awarded without delay. As said, because of Hanover Shoe, each downstream firm can seek a well-defined amount of damages money, even if it was in fact able to pass the larger part (or all) of the anticompetitively raised input price on to the consumers.

In order to establish that the Illinois Wall is an equilibrium under the largest possible threat of damages claims to the tacit arrangement - which forms the tightest incentive constraint for erecting a wall —we assume in the following that at the time of determining the value of the total damages claim, the cartel has existed already since the beginning of time. An upper-bound, for any period $T$, to the total value of an individual retailer's potential damages claim is then given by

$$
\mathbf{D}_{T}=\sum_{t=\tau}^{T} \beta^{T-t} \mu D(p, q) \leq \varphi\left(\mu, \beta, T^{s}\right) D(p, q),
$$

where, as before, $\tau=\max \left\{T_{0}, T+1-T^{s}\right\}$. Here $\varphi\left(\mu, \beta, T^{s}\right)=\sum_{t=T+1-T^{s}}^{T} \beta^{T-t} \mu$, in which $T^{s}$ is set equal to infinity if, for whatever reason, the statute of limitations would not apply. The parameter $\varphi$ is referred to in the following as the 'real' damages multiple and it corresponds to the maximum value of accumulated damages. The value of the real damages multiple increases in the nominal damages multiple $\mu$, the statute of limitations $T^{s}$ and in the damages depreciation factor $\beta$. When damages can only be claimed for one period, obviously, $\varphi(\mu, \beta, 1)=\mu$. Should the damages

firm may have a unilateral incentive to purchase fewer inputs than the $\bar{q}$ offered by the cartel, thus supplying less output against a higher consumer price on its residual demand curve. In Lemma 7 in Appendix A.4, we derive a condition on $(\bar{p}, \bar{q})$ under which $Q_{i}=\bar{Q}$ in equilibrium. In the proof of Theorem 1 in Appendix A.4, it is shown that the Illinois Wall always satisfies this condition. 
claim have been led to accumulate until infinity before the wholesalers' cartel was

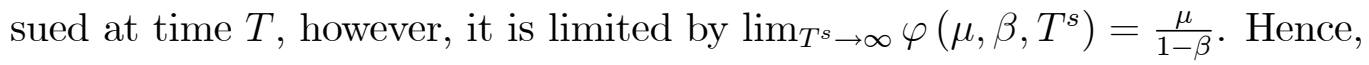

$$
\mu \leq \varphi\left(\mu, \beta, T^{s}\right) \leq \frac{\mu}{1-\beta}
$$

so that $\varphi$ has an upper-bound, because $\beta$ is strictly smaller than $1 .^{26}$

Once the illegal arrangement has been brought to the attention of the authorities, it is discontinued and we assume that the industry will revert to normal competitive Bertrand profits for the rest of time. Hence, maximum total discounted pay-off from filing a private damages suit for each individual downstream firm at time $T$ is

$$
\bar{\Pi}(\bar{p}, \bar{q})+\mathbf{D}_{T}+\sum_{t=T+1}^{\infty} \delta^{t} \Pi^{c} .
$$

In order to be able to raise a stable Illinois Wall, the cartel should choose the pair $(\bar{p}, \bar{q})$ so that for each downstream retailer the present discounted value of the stream of future payoffs under the rationing upstream cartel regime is at least as large as the value of the damages claim plus the discounted value of profits under upand downstream price competition. That is, the downstream firms will refrain from exercising their unique right to claim reparation of antitrust injury if

$$
\frac{1}{1-\delta} \bar{\Pi}(\bar{p}, \bar{q}) \geq \bar{\Pi}(\bar{p}, \bar{q})+\varphi\left(\mu, \beta, T^{s}\right) D(\bar{p}, \bar{q})+\frac{\delta}{1-\delta} \Pi^{c}
$$

where replacing $\mathbf{D}_{T}$ by $\varphi\left(\mu, \beta, T^{s}\right) D(\bar{p}, \bar{q})$ assures that this is indeed the tightest incentive constraint the upstream cartel will ever face. Observe that satisfying the constraint is facilitated by the fact that because the downstream firms are put on allocation at low input prices, the level of actual damages is relatively low, compared to when full upstream cartel prices would have been charged. The 'putting on allocation at low input prices' therefore reduces the retailers' incentive to notify the arrangement in two ways: it increases the per period gains from accepting the bribe for silence, and it lowers the damages total that can be claimed by defecting and filing suit.

Clearly, the possibilities for shielding the cartel depend crucially on whether or not the downstream firms weigh the future benefits from going along with the sidepayment arrangement sufficiently high - as expressed by their common discount factor $\delta$. When, moreover, the upstream industry is able to maintain profits or raise them above the Bertrand level, that is, if $\bar{p} \geq p^{c}$, the Illinois Wall is a subgame-perfect Nash equilibrium. Note that this also assures that the remaining potential damages claim for the downstream firms is non-negative. Furthermore, observe that even though

\footnotetext{
26 Note that the alternative limit assumption, where damages do not depreciate but there is a binding statutory limit, will give a finite upper bound of $\lim _{\beta \rightarrow 1} \varphi\left(\mu, \beta, T^{s}\right)=T^{s} \mu$. Typically, one value of $\varphi$ can represent many different actual antitrust damages practices. See also Section 5.
} 
each retailer is made just indifferent between going along with the collusive arrangement and filing for multiple damages, which makes the anticompetitive arrangement particularly attractive for the upstream cartel, the downstream firms are in no position to demand more of the surplus, for they cannot credibly threaten to sue for damages with the bribe in place. In all, this allows for our main result.

Theorem 1 If $\delta>\delta^{*}$, with

$$
\delta^{*}=\frac{\varphi\left(\mu, \beta, T^{s}\right) p^{c}}{\varphi\left(\mu, \beta, T^{s}\right) p^{c}+\left(1-2 P^{c}\right)},
$$

Illinois Brick sustains the upstream cartel. That is, there exists a pair $\left(\bar{p}^{w}, \bar{q}^{w}\right)$, such that $\bar{\pi}^{w}>\pi^{c}$ and none of the downstream firms has an incentive to exercise its unique right to sue for treble antitrust damages.

The proof of the Theorem is given in Appendix A.4. Some intuition for when an Illinois Wall can be raised, as well as for the relationship between $\delta^{*}$ and the up- and downstream prices in the competitive benchmark, follows from viewing the construction of the wall from the perspective of the upstream cartel. As noted, by choosing $\bar{q}$, the upstream cartel is able to determine consumer prices $\bar{P}=\bar{P}(\bar{q})$, and hence total revenues per variety, $\bar{P}(\bar{q}) \bar{q}$, in the chain-which equal total chain profits, since production costs are normalized to zero. Upstream control is restricted by the need to compensate the downstream retailers for not exercising their right to damages. The second instrument used for this side-payment transfer is the input price $\bar{p}$. The optimal Illinois Wall arrangement now balances the marginal increase in total chain revenues of an increase in $\bar{q}$ with the marginal compensation costs required for it. Consider this problem per variety $i$. Let the per-period compensation costs be denoted by $C_{i}(\bar{q})$. It is easily seen that compensation must at least be equal to the normal competitive profits plus the potential damages claim, so that

$$
C_{i}(\bar{q})=\Pi^{c}+\frac{1-\delta}{\delta} \varphi\left(\bar{p}-p^{c}\right) \bar{q}=\frac{\frac{1-\delta}{\delta} \varphi}{1+\frac{1-\delta}{\delta} \varphi}\left(\bar{P}(\bar{q})-p^{c}\right) \bar{q}+\frac{1}{1+\frac{1-\delta}{\delta} \varphi} \Pi^{c},
$$

where in the last expression the value of $\bar{p}$ that just satisfies incentive constraint (8) with equality is used. ${ }^{27}$ Marginal per-period compensation then is

$$
M C_{i}(\bar{q})=\frac{\partial C_{i}(\bar{q})}{\partial \bar{q}}=\frac{\frac{1-\delta}{\delta} \varphi}{1+\frac{1-\delta}{\delta} \varphi}\left[\frac{\partial \bar{P}(\bar{q})}{\partial \bar{q}} \bar{q}+\left(\bar{P}(\bar{q})-p^{c}\right)\right]
$$

Note that there are two opposing effects on compensation costs from a decrease in $\bar{q}$. The first is a price-effect: a decrease in $\bar{q}$ increases the downstream price $\bar{P}(\bar{q})$ and

27 Substituting $\left(\bar{P}-p^{c}\right) \bar{q}=\left(\bar{P}-\bar{p}+\bar{p}-p^{c}\right) \bar{q}=\bar{\Pi}+D$ and $C_{i}=\bar{\Pi}$ into condition (10) returns (8) holding with equality. Note how this alternative expression brings out very clearly that, as discussed in the text, a decrease in $\bar{p}$ affects the incentive constraint in two ways: it increases the downstream compensation in $\bar{\Pi}$, and it decreases the damages money $D$ that can be sued for. 
thereby the upstream price $\bar{p}$ that is required to keep the downstream firms in the arrangement. This effect is always negative and increases damages. The second effect is a quantity-effect and works in the other direction: if the quantity $\bar{q}$ decreases, the overcharge is calculated over a smaller of units and damages go down. The net result of the price and quantity effects is ambiguous.

The marginal increase in total chain revenues for each variety are

$$
M R_{i}(\bar{q})=\bar{P}(\bar{q}) \bar{q}+\frac{\partial \bar{P}(\bar{q})}{\partial \bar{q}} \bar{q} .
$$

Denote by $q^{m}$ the quantity that maximizes total chain revenues, i.e., $M R_{i}\left(q^{m}\right)=0$. The curves given by (11) and (12) are depicted in Figure 3.

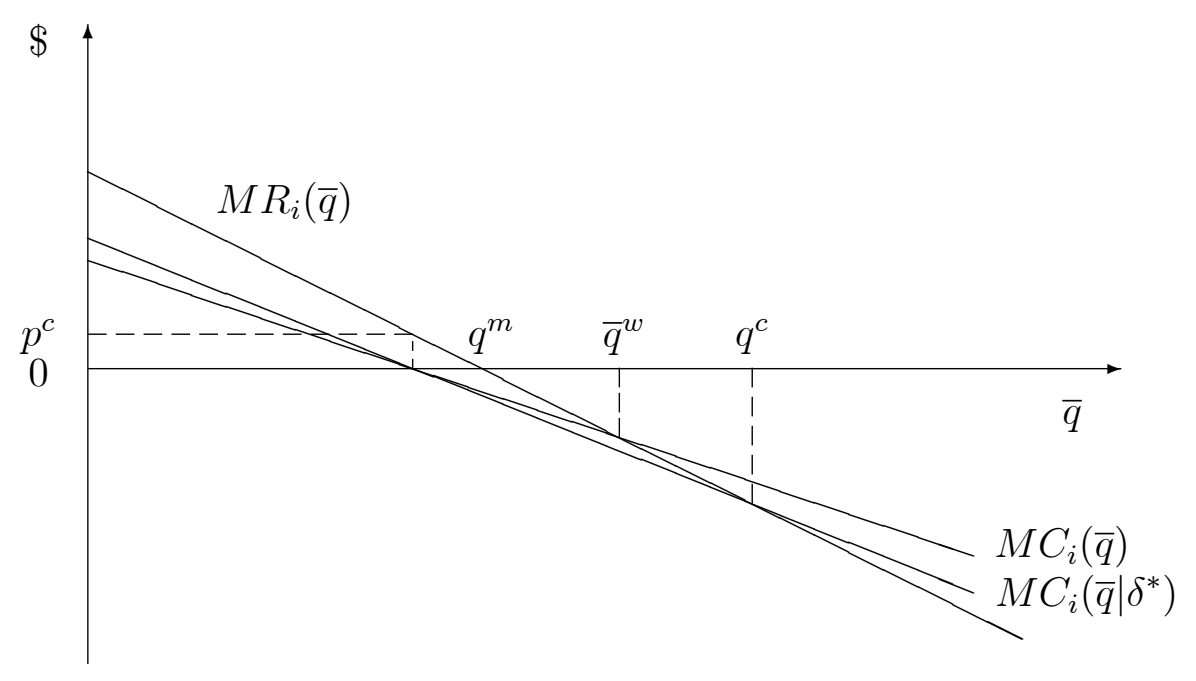

Figure 3: Cartel calculus under the Illinois Wall.

Obviously, as the marginal revenue at the quantity $q^{m}$ is higher than the marginal compensation, it pays for the cartel to increase output beyond the level that would maximize profits for the whole chain.

Variations in the value of $\delta$ and $\varphi$-which in turn varies with $\mu, \beta$ and $T^{s}$ shift the $M C_{i}(\bar{q})$ curve. Lower values of $\delta$ correspond to less patient retailers that demand more compensation to accept the collusive arrangement, which is reflected by a rotation of $M C_{i}(\bar{q})$ through the point where $M C_{i}(\bar{q})=0$, that is, where $M R_{i}(\bar{q})=$ $p^{c}$, so that marginal compensation increases everywhere in absolute value. Higher values of $\varphi$ similarly increase marginal compensation by making claiming damages 
more attractive. As a result, $\bar{q}^{w}$ can lie anywhere between the competitive and the chain profit maximizing quantity $q^{m}$. It is found as the solution to

$$
M R_{i}(\bar{q})=\frac{\frac{1-\delta}{\delta} \varphi}{1+\frac{1-\delta}{\delta} \varphi}\left(M R_{i}(\bar{q})-p^{c}\right) \Leftrightarrow M R_{i}(\bar{q})=-\frac{1-\delta}{\delta} \varphi p^{c}
$$

which reflects that marginal revenue at the optimum is always negative, due to the extra incentive-effect that a decrease in $\bar{q}$ decreases damage.

The critical discount factor that just allows decreasing the input below $q^{c}$ to make the cartel interesting for the upstream firms is found where $\bar{q}^{w}=q^{c}$, as drawn in the figure. In fact, as long as $M R_{i}\left(q^{c}\right)<-\frac{1-\delta}{\delta} \varphi p^{c}$ it pays for the upstream cartel to reduce the quantity $\bar{q}$ below the competitive quantity $q^{c}$, since this will increase revenues more than it will increase the necessary compensation. For the specific model of consumer demand for varieties (1) we use, $M R_{i}\left(q^{c}\right)=2 P^{c}-1$. Therefore the critical value $\delta^{*}$ in Theorem 1 is implicitly given by,

$$
2 P^{c}-1=-\frac{1-\delta}{\delta} \varphi p^{c}
$$

It follows that for all $\delta>\delta^{*}$ we have $M R_{i}\left(q^{c}\right)<-\frac{1-\delta}{\delta} \varphi p^{c}$.

Finally, note that for $M R_{i}\left(q^{c}\right)>0$ there is no value of $\delta$ for which an Illinois Wall exists. In this case, competition is little to begin with, so that the quantity produced in the competitive benchmark is lower than that which would maximize profits if the chains were all fully vertically integrated - that is, when $q^{c}$ lies to the left of $q^{m}$ in Figure 3. Under these conditions, the problem of double marginalization is such that a fully coordinated cartel can increase total welfare over the competitive outcome. $^{28}$ The upstream cartel, just using the simple mechanism of putting the downstream firms on allocation at low prices, cannot achieve this potential welfare gain, however. Even though total industry profits increase when the cartel increases output beyond the competitive level, any feasible Illinois Wall that prevents the retailers from claiming antitrust damages would leave the wholesalers with lower profits than they receive in competition. ${ }^{29}$ The upstream industry simply lacks the instruments, that is, to redistribute the gain in total industry profit that can be achieved by increasing production. Note, however, that an openly fully vertically integrated cartel involving all up- and downstream firms would in these circumstances ask lower consumer prices than prevail under competition. Hence, no party has any damages to sue for under full chain collusion. Consequently, there is no need to use the cumbersome and secretive Illinois Walls mechanism to shield an upstream cartel when markets in the competitive benchmark are highly concentrated.

28 Cf. Spengler (1950), Greenhut and Ohta (1979).

29 It follows from Lemma's 5 and 6 in the appendix that the optimal cartel price, $p^{a}=\frac{1}{2}$, will always be larger than $p^{c}$ for $n \geq 2$ and $e>0$. Moreover, upstream cartel profits are decreasing for $\bar{q}>q^{c}$. 


\section{Resilience of the Wall}

Having established that Illinois Walls can indeed exist, in this section we study their scope in order to see whether they may be a concern. To begin with, observe that the arrangement is so far set in quite adverse conditions. There are, for example, no legal or informational imperfections behind which to hide collusive agreements and escape detection and damages claims. Also, as a result of how we model vertical relationships, there are potentially substantial economic profits in the competitive benchmark, which makes the cooperative agreement harder to sustain. Yet, even in those hostile circumstances, Illinois Walls turn out to exist generically, have serious detrimental welfare effect and be robust.

Consider the space of actual discount factors for which the arrangement is an equilibrium. A period in our model corresponds to one quarter of a year. For ease of comparison, in all numerical analyses below, discount factors have been converted into annual values. It follows immediately from the expression of the critical discount factor in Theorem 1 that $\delta^{*}$ decreases when $p^{c}$ or $P^{c}$ decrease. Hence, the more competitive the up- and downstream industries otherwise are, the more scope there is for erecting an Illinois Wall. Another way in which this effect manifests itself is that $\delta^{*}$ decreases in both $n$ and $e$. Given $n$, for values of $e$ close to one that is, little product differentiation - the value of $\delta^{*}$ will be close to zero. Likewise, for all $e>0$, the limit of $\delta^{*}$ goes to zero as the number of firms grows without bound. Figure 4 pictures how the space of admissible actual discount factors for which the Illinois Wall exists increases in $n$ and $e$ when $\varphi\left(\mu, \beta, T^{s}\right)=48 .{ }^{30}$ A horizontal benchmark line is drawn in at $\delta=0.95$ for comparison.

Clearly, when the industry is more competitive as measured along these two dimensions, the critical discount factor is generally well below typical levels in the 0.9 to 1 region. The reason why it is less difficult to stabilize an Illinois Wall, the more competitive the industry essentially is two-fold. Fierce downstream competition, with output prices close to marginal input costs, implies that the downstream firms pass a larger part (or even all) of their overcharge on to the consumers. Consequently, the monetary incentive to sue for private damages is smaller, as a successful claim will recover the damages money, but has little long term benefits since the true injury from upstream collusion felt downstream is only small. At the same time, more competition in the upstream industry makes the vertical collusion scheme more attractive to each of the upstream wholesalers, compared to competing on prices, so that they each can forward a larger sum in side-payments to the downstream retailers and still profit from the cartel. Hence, the more competitive the chain, the more there is to

\footnotetext{
30 Since all numerical analyses present annual data, $\varphi\left(\mu, \beta, T^{s}\right)=48$ corresponds to treble damages $(\mu=3)$, a statute of limitations of four years $\left(T^{s}=16\right)$ and no depreciation of damages $(\beta=1)$. Alternatively, it can represent a situation in which the statute of limitations does not apply $\left(T^{s} \rightarrow \infty\right)$ and damages depreciating at a rate $\beta=\frac{15}{16} \approx 0.94$ per period. Obviously many other, less extreme, parameter combinations return this specific value of $\varphi$.
} 


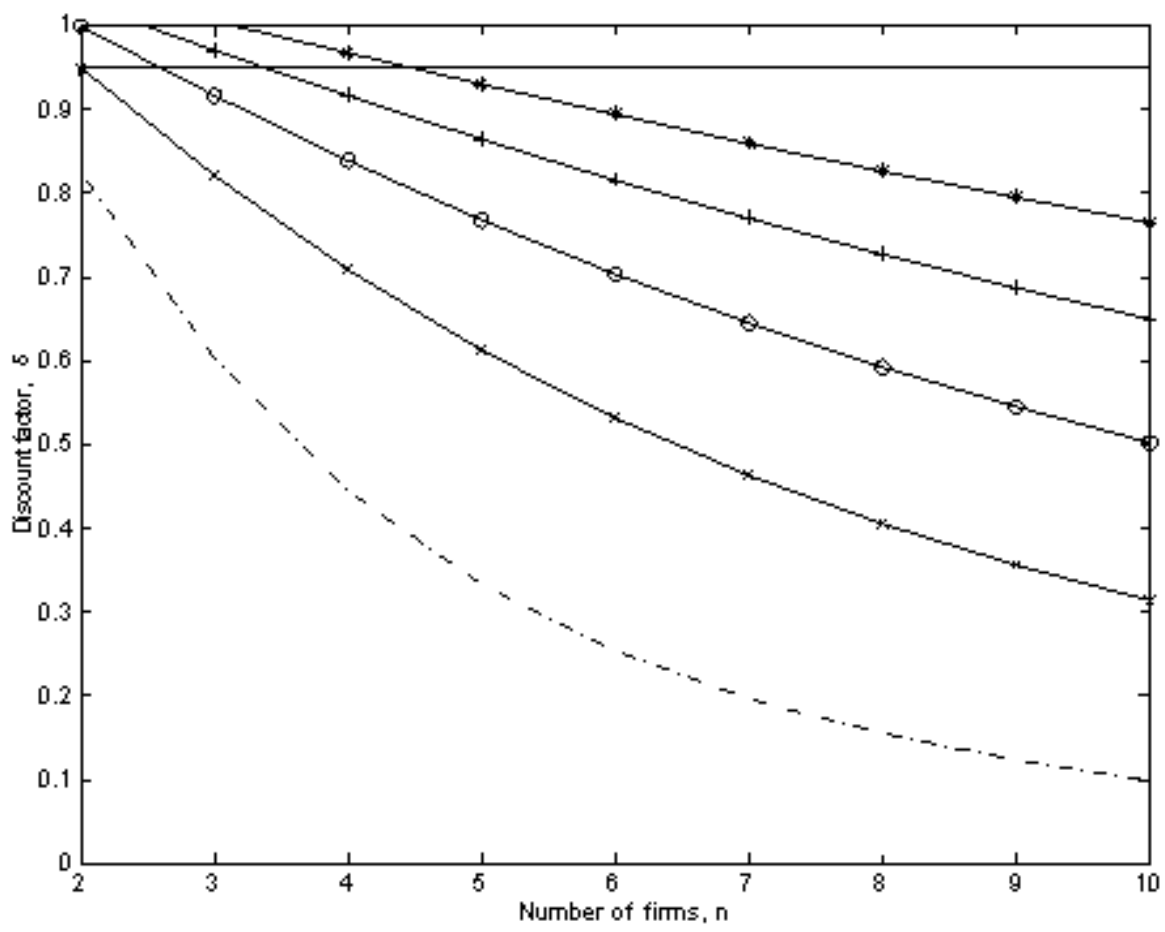

Figure 4: Critical yearly discount factors, as a function of $n$, for different values of $e$-from top to bottom: $e=0.5(*), e=0.6(+), 0, e=0.7(\circ), e=0.8(\times)$ and $e=0.9(-\cdot)$.

gain and redistribute between the wholesalers and the retailers and, therefore, the more scope there is for Illinois Walls.

This interpretation is further substantiated by our analyses of alternative and more competitive market structures in Schinkel and Tuinstra (2005). When, instead of exclusive vertical dealing, each wholesaler supplies at least two retailers, so that downstream shops have a number of different commodities on display and consequently competition drives consumer prices down to input prices, critical discount factors are always lower. Hence, if Illinois Walls exist in the set-up in the text, then they always also exist without exclusive dealing. An even stronger result holds when the upstream industry is more competitive. If all upstream firms produce one and the same homogenous input, which is only converted into differentiated commodities at the retail level, Illinois Walls exist for any positive values of the discount factor. The reason for this is essentially that it is not necessary for the upstream industry to trade-off a stricter rationing of the retailers with higher input price, as there are no upstream profits in the competitive benchmark. Therefore, sufficient side-payments can always be passed-on. Clearly, the potential to abuse Illinois Brick is not limited 
to the type of market structure analyzed in the text. ${ }^{31}$

Figure 5 delineates all forms of competition for which the arrangement is stable. It plots annual iso- $\delta^{*}$ curves that separate all combinations of $e$ and $n$ for which an Illinois Wall exists if the yearly discount rate is at least the value of that specific curve - again for $\varphi=48$. Take the curve $\delta^{*}=0.95$, for example. For all markets to the left of that curve, an Illinois Wall exists if the annual discount rate is at least 0.95. Hence, critical discount factors further out to the upper-right allow larger sets of markets, whereas iso- $\delta^{*}$ curves closer to the origin leave smaller sets. ${ }^{32}$ For market configurations to the left of the dashed line in Figure 5, marginal revenue is positive at the competitive quantity $q^{c}$. As discussed at the end of the previous section, under these conditions it is neither possible, nor practical to use the Illinois Walls mechanism to hide an upstream cartel. Henceforth, we restrict attention to the larger class of markets in which upstream collusion is detrimental to welfare and Illinois Walls are an interesting proposition.

Illinois Walls are a real possibility in a large number of circumstances. But are they generally a concern for welfare? Apart from reducing double mark-ups, the need to hide behind a wall seems to imply that the cartel is disciplined by the amount of patience the retailers have. In particular, $\delta^{*}$ has been determined such that $\bar{p}^{w}=p^{c}$. As a result, one might expect discount factors sufficiently close to $\delta^{*}$ to force the cartel to set prices close to competitive levels, so that welfare losses are negligible. ${ }^{33}$ To see whether this is so, in the upper two panels in Figure 6, welfare losses are set against the number of competing products. The upper left (upper right) panel displays, for $\varphi=48$ and $\delta=0.95$, the ratio of consumer surplus (total surplus) under the Illinois Wall arrangement to consumer surplus (total surplus) under competition. ${ }^{34}$ When $n$ is low, so that the competitive benchmark is poor, the ratio is equal to unity. Yet,

\footnotetext{
31 See Schinkel et al. (2004) for Illinois Walls in a model with homogeneous goods and a variable number of firms that are both up- and downstream horizontally in Cournot competition.

32 Obviously, if $\varphi$ increases at constant values of $\delta$ it likewise becomes more difficult to sustain an Illinois Wall. Note that the level curves in Figure 5 can, therefore, alternatively be interpreted as representing critical values of $\varphi$. Keeping the yearly discount rate fixed at a reasonable value of $\delta=0.95$, the curves thus interpreted correspond, from left to right, to the values $\varphi=48(\circ), \varphi \approx 99$ $(+)$ and $\varphi \approx 154(*)$, respectively.

33 We are indebted to one of the referees for raising this issue.

34 Consumer surplus can be determined as $V(P, \ldots, P, M)=M+\frac{n}{2(1+(n-1) e)}(1-P)^{2}$ - see
} Lemma 2 in Appendix A.1. The relative loss in consumer surplus is measured here as

$$
\triangle C S=\frac{V(\bar{P}, \ldots, \bar{P}, 0)}{V\left(P^{c}, \ldots, P^{c}, 0\right)}=\left(\frac{1-\bar{P}}{1-P^{c}}\right)^{2} .
$$

Similarly, total surplus is $T(P, M)=M+\frac{n}{2(1+(n-1) e)}\left(1-P^{2}\right)$, so that the relative loss in total surplus is equal to

$$
\triangle T S=\frac{1-\bar{P}^{2}}{1-\left(P^{c}\right)^{2}}
$$




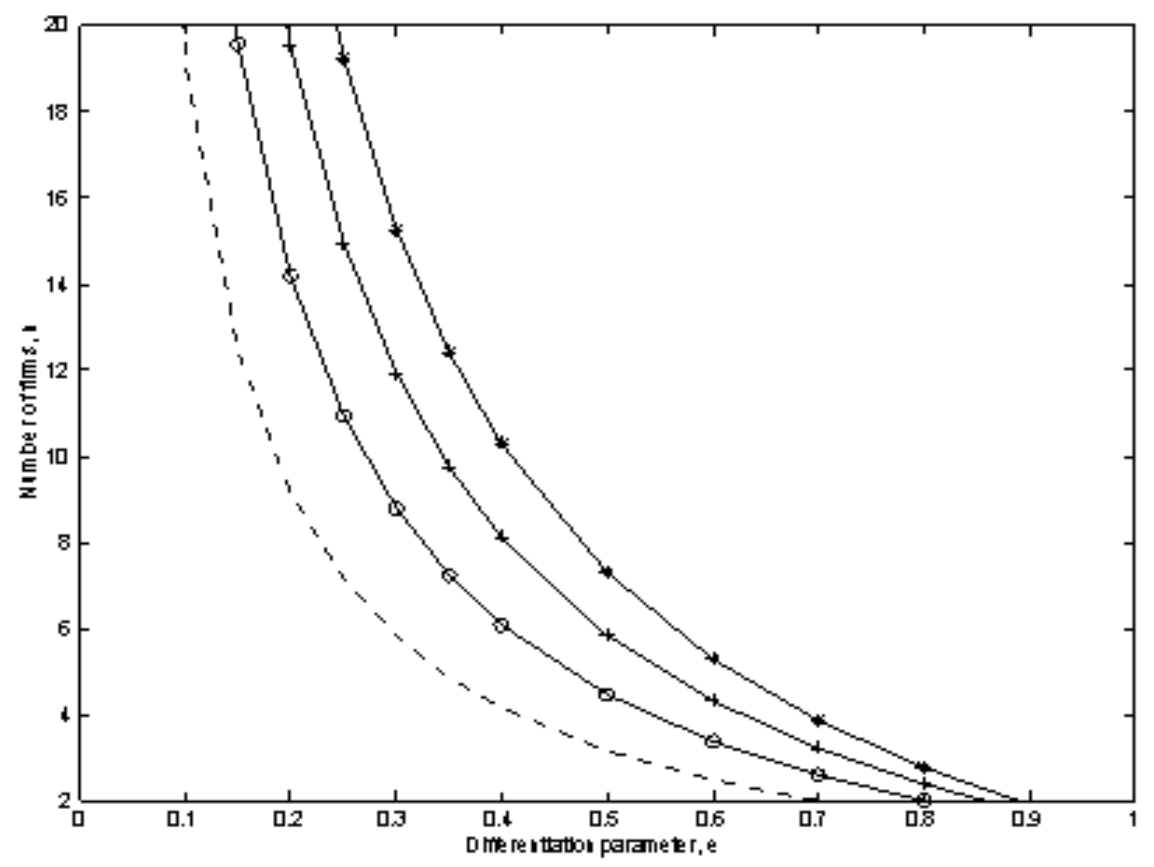

Figure 5: Demarcating iso- $\delta^{*}$ level curves when $\varphi\left(\mu, \beta, T^{s}\right)=48$. From top to bottom: $\delta=0.85(*), \delta=0.9(+)$, and $\delta=0.95(\circ)$.

Illinois Walls become a welfare problem already when there are only few firms, and when they do, their detrimental effect is immediate and substantial. This does not change when the increase in industry profits is taken as part of welfare, as in the right upper panel of Figure 6. Both welfare ratios drop straight from the top line, particularly for low levels of product differentiation. Low discount factors do not discipline the cartel, that is, when there is some competition otherwise. Illinois Walls are a concern whenever they exist.

To study the significance of the real damages multiple, the lower two panels of Figure 6 develop consumer price $\bar{P}$ resulting under the Illinois Wall arrangement for different values of $\varphi$. The unrestricted profit maximizing consumer price $P^{a}$, as well as the competitive price $P^{c}$ are drawn in for comparison. The solid lines represent consumer prices when $\delta=0.95$ and $\delta=0.9$, respectively - the latter returns the steeper line. In the left panel, commodities are more differentiated $(e=0.5)$ than in the right panel, where they are close substitutes $(e=0.9)$. In both, the number of firms is relatively small $(n=5)$. Clearly, $\bar{P}$ decreases linearly in $\varphi$ between $P^{c}$ and $P^{a}$. Although competition is restored between the more differentiated commodities for values of the real damages multiple around that implied by the statutory limit, even very high values of $\varphi$ do not suffice to deter collusion when commodities are 

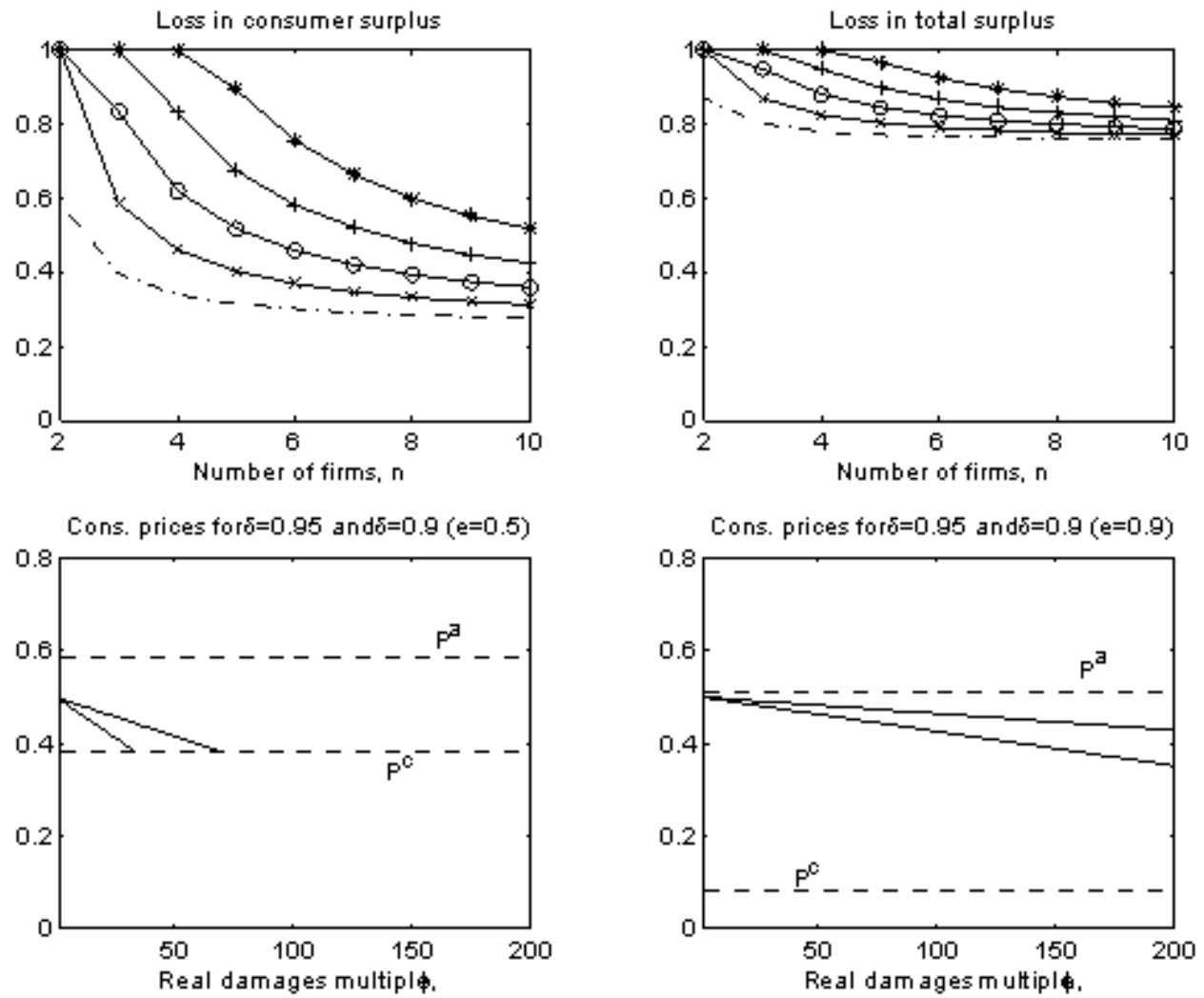

Figure 6: Upper left and right panels: Consumer surplus and total surplus under the Illinois Wall as a fraction of consumer surplus and total surplus under competition, for $\delta=0.95, \varphi=48$ and different values of $n$. From top to bottom: $e=0.5(*)$, $e=0.6(+), e=0.7(\circ), e=0.8(\times)$ and $e=0.9(-\cdot)$. Lower left and right panels: Consumer prices for varying levels of $\varphi$. Left panel: $n=5$ and $e=0.5$. Right panel: $n=5$ and $e=0.9$. From top to bottom: $P^{a}, \bar{P}$ for $\delta=0.95(*), \bar{P}$ for $\delta=0.9(+)$ and $P^{c}$.

close substitutes.

Finally, note in the lower two panels that when $\varphi$ approaches zero, so that private antitrust damages claims are impotent, $\bar{P}$ goes to $\frac{1}{2}$-and not, for example, to $P^{a}$. This illustrates how the control that the Illinois Wall arrangement gives the upstream firms over their retailers is constrained by the double use of instruments. If the cartel can determine downstream behavior without the need to ward off damages claims (that is, if $\varphi=0$ ), it is able to fully eliminate the double mark-up problem and set consumer prices as if each chain were fully vertically integrated.

In order to study resilience of the wall, first consider the threat of disclosure and entry. We claim that the protection offered by Illinois Brick is such, that the upstream cartel can be quite open about its horizontal activities. In the absence of public cases, 
everyone can have access to enough evidence of its existence to substantiate a private damages claim - in fact, under the Illinois Wall, the downstream firms need to have sufficient evidence to credibly threaten the cartel with a claim. On the other hand, the vertical side-payment arrangement needs to be kept a strict secret for consumers - and other indirect purchasers. So consumers may know that they pay anticompetitively raised prices, but they do not understand - or at least they cannot prove - how the chain profits therein are distributed between the wholesalers and the retailers. Note that this leaves many possibilities for vertical communication in the chain, as long as evidence of it, sufficient to argue convincingly that the vertical arrangement existed, does not fall into the hands of the consumers. The information issues play between distinct groups, that is.

While the relative safe-haven provided by the Illinois Wall allows the wholesalers to meet in smoke-filled rooms and discuss their conspiracy, which may help them to keep it stable, there is no need for them to shout the existence of their cartel from the rooftops. ${ }^{35}$ No one outside of the industry needs to know about it. Should profits in the upstream industry nevertheless attract potential entrants, this is no different than the classical cartel entry problem. Downstream, on the other hand, entrants that present themselves pose a potential threat that is particular to the Illinois Wall arrangement. If, for example, the downstream firms ask from the cartel not to allow the new entrant in by refusing to supply it with inputs, the potential entrant could attempt to bring an antitrust case on the grounds of refusal to deal, which - although typically difficult for new entrants to substantiate - as a provable infringement of competition law may threaten the stability of the wall. For this reason - and with the extra benefit that it lowers the critical discount factor - the incumbent retailers may want to assimilate new entrants into the tacit agreement, rather than compete with them or trigger legal battles. Although none of the participants in an existing Illinois Wall arrangement would welcome entry, it is resilient to this pressure.

It should in this context also be noted that even though Illinois Walls exist for lower discount factors, the more firms are involved, an increase in the number of either up- or downstream firms, or both, also introduces issues of coordination and stability. As in ordinary cartels, the larger the number of firms in the upstream industry, the more strain will be put on the horizontal collusive arrangement. Whether it can remain is essentially a matter of sufficient patience again. Hence, there are two conflicting effects of more upstream firms here: on the one hand, it widens the space of discount factors for which Illinois Walls exist, while on the other hand it narrows the possibilities for sustaining the horizontal part of it. Likewise, note that large numbers of downstream firms may make it difficult for all of them to understand how it is exactly that they benefit from the Illinois Wall arrangement. We have shown how, independently of the number of firms involved, all downstream firms are willing to accept the level of input at which they are being put on allocation at low prices. Furthermore, the side-payments have been set at a bare minimum, just to

35 See McCutcheon (1997) and the references therein given. 
make the downstream firms indifferent between joining the arrangement or filing suit. Typically, however, there are financial windfall gains upstream for the cartel that it could apply, if necessary, to being more munificent in trying to keep on the right side of the downstream firms. Yet, the probability that consumers get wind of the arrangement, or that one of the retailers strays and brings the arrangement to light by erroneously filing an antitrust damages claim arguably increases in the complexity of the industry. Although these observations merit more precise modelling, such would merely qualify the shape and form of the Illinois Walls, and certainly not topple them.

The assumptions made so far about the availability of public information and the related efficiency of the legal system can also be relaxed. We have shown that Illinois Walls are stable, even when the existence of the upstream cartel is common knowledge and the legal system is perfect in the handling of private damages cases. If information would be less than perfect, asymmetric - as in the argument that the direct purchasers are more efficient detectors than consumers - or if the judicial system involves nonnegligible costs, or if the eventual conclusions of law, even when a case does in fact have merit, a priori are uncertain, then bringing a private antitrust case would only be hindered further. The reason for this is that then the eventually awarded net damages money and thereby the private incentives to sue for them would be reduced. ${ }^{36}$ This would enhance the scope for erecting Illinois Walls. Analytically, it corresponds to a reduction in $\varphi$, which decreases the value of $\delta^{*}$.

The same is not true of we introduce public antitrust enforcement into the picture. Where those advocating Hanover Shoe and Illinois Brick would typically consider private enforcement to be superior over public enforcement, the latter turns out to be a desirable complement to the former when Illinois Walls are a possibility. Public cases, no different from private ones, will put stress on both the horizontal and the vertical cartel arrangements, thus potentially undermining them. Although the incentive for public officials to bring anticompetitive practices to light may indeed be less than that of private parties themselves affected in their well-being by the cartel prices, surely the antitrust authorities are a major player in this game. And should government still miss them, parens patriae provisions for consumers and indirect purchasers to file complaints on the anticompetitive behavior of upstream firms that are out of their reach by Illinois Brick with their state antitrust enforcers or the Department of Justice would clearly provide an incentive - albeit by far not to the extent provided by the treble damages reward - to notify cases to the authorities. ${ }^{37}$ Likewise, other interested parties, such as shareholders, may defend their interest in a court case. Yet, under reference to the previous observation that imperfect and asymmetric information would fortify Illinois Walls, we believe that in a world with less than perfect information, public enforcement is no guarantee for full-proof protection against collusion.

\footnotetext{
36 Cf. Lande (1993).

37 Cf. also J. Truett Payne Co., Inc. v. Chrysler Motors Corp. 451 U.S. 557 (1981) discussed in the introduction.
} 
Finally, we are confident that extensions of our simple model to, for example, non-linearity in demand or alternative cost structures, will not change our qualitative findings. Likewise, Illinois Walls surely are a possibility in longer vertical chains, or chains that involve a larger number of upstream than downstream firms, or vice versa. Moreover, it is likely that there are further types of Illinois Walls based on different punishment strategies - such as forms of intertemporally alternating putting on allocation, or a restoration in time of the collusive agreement if the wall happened to come down.

\section{Are We Facing Illinois Walls?}

Pointing out a robust theoretical possibility as we do raises the question whether there is any indication that Illinois Walls are indeed a reality. Levenstein and Suslow (2004) argue that large customers need not always undermine cartels, as they may be implied in the arrangement. The authors present several well-documented cartels in which the distributors, rather than the manufacturers on whom investigations centered at the time, were essential to the success of the cartel - typically by preventing entry into the chain - and in return shared in the cartel rents. ${ }^{38}$ Yet, actual Illinois Walls would require such implications to be designed with an eye to keeping the downstream firms from claiming private damages. The easy answer to the question of whether such arrangements indeed exist is, of course, that by their nature, Illinois Walls escape direct observation: they are tacit, hidden and silent. Moreover, so far their possible existence was unknown. Only through specifically targeted antitrust investigations may Illinois Walls, therefore, perhaps be found out about in future enforcement. As this may not be sufficient answer, however, we have gone back and considered some unmasked, post-Illinois Brick cartels to see if they displayed symptoms of what could have been vertical arrangements that tied downstream purchasers into an upstream suppliers cartel. As it turns out, there is, in fact, some direct indication of essential characteristics of our Illinois Wall example in some recent high profile cases.

In the Brand Name Prescription Drugs antitrust litigation, a class action for antitrust damages brought in the early 1990's by a number of retail pharmacists against several pharmaceutical manufacturers - claiming that the manufacturers had price discriminated between them and the larger health care organizations, thus putting the plaintiffs at a competitive disadvantage - there was a direct argument that the wholesalers, who stood between the retailers and the manufacturers, were implied in the alleged conspiracy. ${ }^{39}$ That is, the manufacturers and wholesalers had jointly developed a computerized system to handle the complicated administrative process

\footnotetext{
38 In particular, the American 'bromine pool' and Standard Oil had-albeit obviously well before the Illinois Brick rule - such characteristics. See Levenstein and Suslow (2004), p.26 and the references therein given.

39 Cf. In re: Brand Name Prescription Drugs Antitrust Litigation, MDL No. 997, No. 94 C 897. We thank Bob Larner for pointing us to this Illinois Brick reference.
} 
of calculating the various discounts in the chain. This so-called 'chargeback' system was alleged to involve the wholesalers in the upstream cartel, giving them a stake in the collusive profits. The court ruled that the wholesalers were indeed eliminated as an independent control in the chain, so that the plaintiffs were effectively direct purchasers and thus entitled to damages under Illinois Brick. The case was settled in 1996, when the majority of drug manufacturers agreed to pay the retail pharmacists damages totally $\$ 351$ million. ${ }^{40}$

Although many public antitrust prosecutions originate in private notifications, in a number of recent cases brought by the DOJ that were widely publicized, the direct purchasers were, in fact, conspicuous by their absence. In October 1996, Archer Daniels Midland Co. agreed to plead guilty and pay a record criminal antitrust fine of $\$ 100$ million for its role in a worldwide price fixing conspiracy in the markets for lysine and citric acid. ${ }^{41}$ ADM followed the earlier confessions of involved Japanese and Korean companies, who together paid $\$ 20$ million in fines. Lysine gained some fame through the footage of cartel meetings shot by FBI infiltration. On the lysinetapes, the conspiring chief executives - several of which were later handed prison sentences - are overheard and seen to agree, fully aware of the illegal nature of their meetings, on prices and volumes scribbled on a white board. Also, the dominant American executive of ADM impresses upon his Asian coconspirators the importance of being 'close friends', and how ADM's excess capacity would need to be used in case of any misunderstanding. The success of Lysine was repeated by the DOJ a few years later when it uncovered, again with the help of the FBI, yet another large global conspiracy of bulk inputs, this time in vitamins, which involved BASF and Hoffmann-La Roche. ${ }^{42}$ In 2000, criminal fines were given to the companies, as well as prison sentences to some of their chief executives.

The lysine-tapes, as well as further investigatory techniques applied in Vitamins, educated competition law enforcers - as well as the business community. One important lesson drawn from this and other experiences by William Kolasky, at the time Deputy Assistant Attorney General at the DOJ's Antitrust Division, is that:

"[T]he ability of large sophisticated buyers to defeat cartel activity may be overrated. [...] In the lysine cartel, the buyers included Tysons Foods and Con Agra; in citric acid, the buyers included Coca-Cola and Procter\&Gamble; and in graphite electrodes, the victims included every major steel producer in the world." (Kolasky, 2002, p.18)

It is at least peculiar that the direct purchasers of these conspirators were not instrumental in bringing the cartel arrangements to light. One would expect, for example,

\footnotetext{
40 See Scherer (1997) for a critical review of the case.

41 Cf. United States of America v. Ajinomoto Co., Inc. et al., No. 96-CR 520-1996. We thank Margaret Levenstein and Bill Kovacic for suggesting Lysine and also Vitamins as examples of peculiar downstream passiveness, possibly indicating implication.

42 Cf. Vitamins Antitrust Litigation, No. 99-197 TFH, 2000 WL 1737867.
} 
some of the larger clients to have experienced trouble in attempting to order volumes above the cartel quota. No complaints, for example for refusal to deal, where made, however. Perhaps that was because that sort of a thing is not on the minds of managers. Perhaps also the direct purchasers were not fully innocent 'victims' at all, as Kolasky implicitly assumes, but rather had some so far unacknowledged interest that prevented them from denouncing the cartel.

Another important case in which the direct purchasers were far from instrumental in unmasking anticompetitive behavior of their dominant supplier is noted in Lopatka and Page (2004). The paper is an argument against repealing Hanover Shoe and Illinois Brick at the federal level, essentially on the observation that for the majority of cases in which the indirect purchasers filed suit, these were followon damages claims by direct purchasers. Lopatka and Page infer from this that "experience shows that direct purchasers are not reluctant to sue." 43 Although this does not seem to evidence that not still possibly many direct purchasers may have been hesitant to claim, it is particularly interesting that the authors themselves note one striking exception to their generalization in U.S. v. Microsoft Corp.. ${ }^{44}$ In this public case, even in the follow-on litigation, although indirect purchasers filed class action suits against Microsoft wherever state law gave them standing to sue, none of Microsoft's direct purchasers - that is, original equipment manufacturers (OEMs) that pre-installed Microsoft software prior to shipping their computers - has to date brought a claim against the company for damages. If indeed Microsoft's exclusionary and levying practices allowed it to charge sustained anticompetitively high prices for its software, the OEM's would have been hurt by this, and presumably have known so. Again, however, the DOJ instigated the case on complaints of rivals, not the direct purchasers, which led Lopatka and Page to suggest that:

"[S] ome OEMs may have received compensation in return for cooperating in restrictive practices, compensation that would in principle reduce the amount of damages." (op. cit., p.563)

This is exactly the effective principle in our Illinois Wall example.

The Illinois Wall principle of 'putting on allocation' has furthermore been revealed to exist in a recent private damages case that did come to federal court, Holiday Wholesale. ${ }^{45}$ In this class action of wholesalers and retailers against four U.S. tobacco companies that together held $95 \%$ of the market for cigarettes, one of the plaintiffs' arguments was that the tobacco companies abused their joint dominance through a permanent allocation program. The manufacturers determined the

\footnotetext{
43 Lopatka and Page (2004), p.561.

44 Cf. United States of America v. Microsoft Corporation, No. 98-1232.

45 Cf. Holiday Wholesale Grocery Co. et al., v. Philip Morris Incorporated, et al., No. 1:00CV-0447-JOF. We are indebted to Frank Fisher for pointing us to this example of intermediaries that complained - as it seemed against their own interest - against being 'put on allocation' by their suppliers.
} 
number of cigarettes each wholesaler could yearly distribute, using a system in which each of them was allowed only a small increase over the purchases of the previous year, unless wholesalers could show that they had acquired new retail customers. The tobacco companies argued that this system was in the interest of efficiency, for it allowed them to determine true consumer demand by keeping the wholesalers from engaging in speculative stock accumulation - also referred to as 'trade loading'. Also, it would reduce the amount of product returns in an efficient manner. In the end, the court found no evidence that the allocation programs indeed restricted the output of cigarettes. Also, it took the view that the alleged collusive arrangement was, in fact, the result of uncoordinated choices in an oligopolistic market. As a result, the defendants' motion for summary judgement was eventually granted in 2002. Yet, perhaps the vertical rationing system was a poorly understood compensation scheme that, if it had not come down and into the open, we would never have known about.

A similar symmetric rationing scheme to the benefit of intermediaries may well have been the secret of the steady success of the De Beers diamond cartel. In July 2004, De Beers pleaded guilty to price fixing charges after being indicted by the DOJ for the U.S. district court in Columbus, Ohio in 1994. Paying $\$ 10$ million in criminal fines, it settled an impasse that had prevented its employees from travelling in America out of fear for being arrested since World War II. ${ }^{46}$ The cartel's business model has always been to offer in its London based Central Selling Organization, on a limited number of occasions per year only, sorted bundles of rough diamonds to a small group of selected clients at non-negotiable prices. These favoured "sightholders" would then cut and polish the rough stones, before selling them on in the chain to retailers and eventually to final consumers. Although emphasis has primarily been on the benefits that accrued to De Beers itself from creating this artificial scarcity and consequential high prices, the select group of sightholders is likely to have benefitted as well. Although the quality of the lots on take-it-or-leave-it offer would vary, each of the sightholders knew the offer to their competitors would be equally restricted in size and quality, in ways that evened out fairly symmetrically over time. It is again remarkable, to say the least, that no private action to recover antitrust damages against this textbook example of a cartel was brought in the past.

All these examples remain anecdotal evidence, however. Therefore, a more consistent empirical study into the matter seems called for. Yet, as discussed in the introduction, such studies in Landes and Posner (1979), Joyce and McGuckin (1986) and Snyder (1986), in which the total number of private damages cases brought over time displays structural breaks around the Hanover Shoe and Illinois Brick rulings, has remained largely inconclusive. An interesting possibility for a novel statistical approach to our hypothesis is offered, however, by the 1989 ARC America, also mentioned in the introduction. Since the number of Illinois Brick repealers has since the early 1990's grown steadily to presently include roughly half of the states, the presence

46 Cf. United States of America v. General Electric Company, De Beers Centenary AG, et al., No. CR-2-94-019-1994. See also The Economist, "The Cartel Isn't For Ever," 15 July, 2004. 
of Illinois Walls could be investigated by comparing the number of direct purchaser suits in states that followed Hanover Shoe and Illinois Brick with those in Illinois Brick repealers. Our hypothesis would be that, corrected for cartel incidence - for example by some measure of industrial activity - Illinois Brick repealers would see a significantly higher number of antitrust damages claims filed by direct purchasers - or in total, if the position in the chain is not easily determined from the files. Although this seems to be a promising approach, it is potentially quite troublesome. The possibilities for indirect purchasers vary between the repealers and are in fact, ineffective in some. Also some states readily certify classes, while others rarely do so, which decreases the number of private damages cases in the latter, but not due to Illinois Brick. More importantly, the data available on private damages claims is very incomplete, due to the large percentage of them that is settled out of court or dismissed. As a result, consistent statistics are not readily available and allegedly difficult to compile. ${ }^{47}$ We therefore leave such direct empirical tests for future research.

\section{Concluding Remarks}

We have identified a so far largely ignored anticompetitive effect of the influential twin Supreme Court rulings in Hanover Shoe and Illinois Brick. Clearly, possibilities for passing-on upstream cartel profits in the production chain are plentiful. Several aspects important for understanding the full effect of private damages claims we have set aside in order to offer an unobstructed view on the strategic role that Illinois Brick can play in stabilizing chain collusion in our example. As a result, the setup of our model is simple. Yet, we believe it captures the nature of the anticompetitive effect Illinois Brick may have. We have shown that the Illinois Wall is generic, has serious welfare consequences and is resilient to extensions in a number of directions.

Moreover, we believe our model approach offers several handles to study the passon of cartel benefits in vertical production chains more generally — as said, a practice observed by others before us to occur in collusive agreements. These pass-ons can have interesting implications for vertical (dis)integration and double-marginalization problems. Producers may want to use them in trying to coordinate, at least partially, around these issues in modestly concentrated markets. Closer to our original idea, vertically allocated cartel profits can help sustaining socially unwanted restrictions of trade in less hostile circumstances than the U.S. clear and present danger of massive treble damages suits. They are relevant for the Europe Union and its Member States, for example, where a private antitrust damages practice is still in it infancy - in part because multiple damages are not available - and restrictions on standing to sue for antitrust damage reparation are being discussed. ${ }^{48}$

\footnotetext{
47 We are indebted to William Page and Robert Lande, who both pointed out some of these difficulties that would potentially interfere with finding unbiased results in the suggested approach. 48 Cf. Wils (2003).
} 
On the issue of Illinois Brick, we do acknowledge that we have not dealt more than in passing with the larger part of the rule's potential for efficiency gain, in particular the savings on legal transaction costs it is likely to bring about. We have abstracted from these potential gains that have been the focus of attention in most of the relevant literature, only in order to contribute a new argument to the debate. Our efficiency argument against Illinois Brick adds to the existing opposition to the doctrine, based on fairness objections and a low assessment of the legal transaction costs involved in antitrust damages cases. Obviously, for a full understanding of the complex incentive issues that play in private antitrust enforcement, a balancing of all the arguments is essential. Such comprehensive judgements we leave for others to make.

It nevertheless seems that the possible abuse of the twin Supreme Court positions in Hanover Shoe and Illinois Brick to construct Illinois Walls in vertical production chains merits notification, and cannot be as easily discarded as the early literature did. Its negative welfare effects need to be taken into consideration and weighted against the potential efficiency gains of Illinois Brick and Hanover Shoe that have so far been forwarded. Because of its relevance to many prominent antitrust cases since the late 1970's, and some indication that Illinois Walls may indeed exist, the perverse possibility that Illinois Brick offers upstream firms to ward off private antitrust cases deserves acknowledgement. 


\section{A Bricks for the Wall: Proofs and Intermediate Results}

\section{A.1 Foundations of Consumer Demand}

Lemma 1 Suppose the representative consumer's utility function is given by

$$
U\left(Q_{0}, Q_{1}, Q_{2}, \ldots, Q_{n}\right)=Q_{0}+a \sum_{i=1}^{n} Q_{i}-\frac{1}{2}\left(b \sum_{i-1}^{n} Q_{i}^{2}+e \sum_{i=1}^{n} \sum_{j \neq i} Q_{i} Q_{j}\right)
$$

where $Q_{i}, i=1, \ldots, n$, are differentiated varieties of the commodity under consideration, $e \in[0,1)$ is a measure of substitutability between these different varieties, $a$ and $b$ are preference parameters and $Q_{0}$ is a composite commodity with price equal to one and which represents expenditures on all other available commodities. Assuming that $a=b=1$ the demand for variety $i, i=1, \ldots, n$, is given by

$$
\begin{aligned}
Q_{i}\left(P_{1}, \ldots, P_{n}\right) & =\frac{1-e-(1+(n-2) e) P_{i}+e \sum_{j \neq i} P_{j}}{(1+(n-1) e)(1-e)} \\
& =\frac{(1-e)\left(1-P_{i}\right)-e \sum_{j \neq i}\left(P_{i}-P_{j}\right)}{(1+(n-1) e)(1-e)} .
\end{aligned}
$$

Proof. Let the consumer have budget $M$ to spend. He or she seeks to maximize utility given the budget constraint. The Langrangian for this problem is

$$
\begin{aligned}
L\left(Q_{1}, \ldots, Q_{n}, \lambda\right)= & Q_{0}+\sum_{i=1}^{n} Q_{i}-\frac{1}{2}\left(\sum_{i-1}^{n} Q_{i}^{2}+e \sum_{i=1}^{n} \sum_{j \neq i} Q_{i} Q_{j}\right) \\
& +\lambda\left(M-Q_{0}-P_{1} Q_{1}-\ldots-P_{n} Q_{n}\right) .
\end{aligned}
$$

Provided that $M$ is large enough, the first-order condition associated with $Q_{i}$ is

$$
1-Q_{i}-e \sum_{j \neq i} Q_{j}-P_{i}=0,
$$

for $i=1, \ldots, n$ and

$$
1-\lambda=0,
$$

for $i=0$, so that $\lambda=1$. Using this, and solving the system of the $n$ first-order conditions 
for varieties 1 up to $n$ we find that

$$
\begin{aligned}
\left(\begin{array}{c}
Q_{1} \\
Q_{2} \\
\vdots \\
Q_{n}
\end{array}\right)= & \left(\begin{array}{cccc}
1 & e & \cdots & e \\
e & 1 & & \vdots \\
\vdots & & \ddots & e \\
e & \cdots & e & 1
\end{array}\right)^{-1}\left(\begin{array}{c}
1-P_{1} \\
1-P_{2} \\
\vdots \\
1-P_{n}
\end{array}\right) \\
= & \frac{1}{(1+(n-1) e)(1-e)} \times \\
& \left(\begin{array}{cccc}
(1+(n-2) e) & -e & \cdots & -e \\
-e & \ddots & & \vdots \\
\vdots & & \ddots & -e \\
-e & \cdots & -e & (1+(n-2) e)
\end{array}\right)\left(\begin{array}{c}
1-P_{1} \\
1-P_{2} \\
\vdots \\
1-P_{3}
\end{array}\right),
\end{aligned}
$$

which is demand system (1). Furthermore, demand for the composite good follows from the budget constraint as

$$
Q_{0}=M-\sum_{i=1}^{n} P_{i} Q_{i}
$$

Note that demand for each of the different varieties is independent of $M$, if $M$ is large enough. Variations in $M$ will only influence the demand for the composite good.

Lemma 2 When all varieties are equally priced, i.e., $P_{i}=P$ for $i=1, \ldots, n$, the indirect utility function can be written as

$$
V(P, \ldots, P, M)=M+\frac{n}{2(1+(n-1) e)}(1-P)^{2} .
$$

Total surplus (consumer welfare plus industry profits) are

$$
T(P, M)=M+\frac{n}{2(1+(n-1) e)}\left(1-P^{2}\right)
$$

Proof. When all prices are equal we obtain from (1) that demand for each commodity is

$$
Q(P) \equiv Q_{i}(P, \ldots, P)=\frac{(1-P)}{(1+(n-1) e)} \text { for } i=1, \ldots, n .
$$

Consequently, indirect utility at uniform prices is found as

$$
\begin{aligned}
V(P, \ldots, P, M) & =M-n P Q+\left(n Q-\frac{1}{2}\left(n Q^{2}+e n(n-1) Q^{2}\right)\right) \\
& =M+\frac{1}{2} n((n-1) e+1) Q^{2} \\
& =M+\frac{n}{2(1+(n-1) e)}(1-P)^{2} .
\end{aligned}
$$


Total surplus is given by

$$
\begin{aligned}
T(P, M) & =V(P, \ldots, P, M)+n P Q(P) \\
& =M+\frac{n}{2(1+(n-1) e)}(1-P)^{2}+n P \frac{(1-P)}{(1+(n-1) e)} \\
& =M+\frac{n}{2(1+(n-1) e)}\left(1-P^{2}\right) .
\end{aligned}
$$

\section{A.2 The Competitive Benchmark}

Lemma 3 Given the input prices $\left(p_{1}, \ldots, p_{n}\right)$, the following Bertrand-Nash equilibrium prices establish in the downstream industry

$$
P_{i}=A_{e, n}^{\prime}\left(B_{e, n}^{\prime}+C_{e, n}^{\prime} p_{i}+D_{e, n}^{\prime} \sum_{j \neq i} p_{j}\right)
$$

where

$$
\begin{aligned}
A_{e, n}^{\prime} & =\frac{1}{4+6(n-2) e+\left(2 n^{2}-9(n-1)\right) e^{2}} \\
B_{e, n}^{\prime} & =(2+(2 n-3) e)(1-e) \\
C_{e, n}^{\prime} & =(2+(n-2) e)(1+(n-2) e) \\
D_{e, n}^{\prime} & =e(1+(n-2) e) .
\end{aligned}
$$

Proof. Firm $i$ sets $P_{i}$ in order to maximize profits $\left(P_{i}-p_{i}\right) Q_{i}\left(P_{1}, \ldots, P_{n}\right)$. Using (1), the first-order condition for firm $i$ is

$$
2(1+(n-2) e) P_{i}-e \sum_{j \neq i} P_{j}=\xi_{i} \equiv 1-e+(1+(n-2) e) p_{i} .
$$

Solving the system of $n$ first-order conditions, the Bertrand-Nash competitive benchmark equilibrium prices are

$$
\begin{aligned}
\left(\begin{array}{c}
P_{1} \\
P_{2} \\
\vdots \\
P_{n}
\end{array}\right) & =\left(\begin{array}{cccc}
2(1+(n-2) e) & -e & \cdots & -e \\
-e & \ddots & & \vdots \\
\vdots & & \ddots & -e \\
-e & \cdots & -e & 2(1+(n-2) e)
\end{array}\right)^{-1}\left(\begin{array}{c}
\xi_{1} \\
\xi_{2} \\
\vdots \\
\xi_{n}
\end{array}\right) \\
& =A_{e, n}^{\prime}\left(\begin{array}{cccc}
2+(n-2) e & e & \cdots & e \\
e & \ddots & & e \\
\vdots & & \ddots & \vdots \\
e & e & \cdots & 2+(n-2) e
\end{array}\right)\left(\begin{array}{c}
\xi_{1} \\
\xi_{2} \\
\vdots \\
\xi_{n}
\end{array}\right)
\end{aligned}
$$


where

$$
A_{e, n}^{\prime}=\frac{1}{4+6(n-2) e+\left(2 n^{2}-9(n-1)\right) e^{2}},
$$

and the other parameters follow straightforwardly.

Lemma 4 The implied demand for upstream firm $i$ is given by

$$
q_{i}\left(p_{1}, \ldots, p_{n}\right)=A_{e, n}-B_{e, n} p_{i}+C_{e, n} \sum_{j \neq i} p_{j}
$$

where

$$
\begin{aligned}
A_{e, n} & =\frac{1}{1+(n-1) e} \frac{2+(4 n-7) e+(2 n-3)(n-2) e^{2}}{4+6(n-2) e+\left(2 n^{2}-9(n-1)\right) e^{2}}>0 \\
B_{e, n} & =\frac{1+(n-2) e}{(1+(n-1) e)(1-e)} \frac{2+3(n-2) e+\left(5-5 n+n^{2}\right) e^{2}}{4+6(n-2) e+\left(2 n^{2}-9(n-1)\right) e^{2}}>0 \text { and } \\
C_{e, n} & =\frac{1}{(1+(n-1) e)(1-e)} \frac{e(1+(n-2) e)^{2}}{4+6(n-2) e+\left(2 n^{2}-9(n-1)\right) e^{2}}>0 .
\end{aligned}
$$

Proof. Input prices $\left(p_{1}, \ldots, p_{n}\right)$ give rise to the downstream Bertrand-Nash equilibrium prices $\left(P_{1}\left(p_{1}, \ldots, p_{n}\right), \ldots, P_{n}\left(p_{1}, \ldots, p_{n}\right)\right)$, which implies that the input demand of downstream firm $i$ for the product of upstream firm $i$ is given by

$$
q_{i}\left(p_{1}, \ldots, p_{n}\right)=Q_{i}\left(P_{1}\left(p_{1}, \ldots, p_{n}\right), \ldots, P_{n}\left(p_{1}, \ldots, p_{n}\right)\right) .
$$

For ease of exposition we write (1) and (2) as

$$
\begin{aligned}
Q_{i}\left(P_{1}, \ldots, P_{n}\right) & =f\left(a-b P_{i}+e \sum_{j \neq i} P_{j}\right) \text { and } \\
P_{i}\left(p_{1}, \ldots, p_{n}\right) & =\alpha+\beta p_{i}+\gamma \sum_{j \neq i} p_{j}
\end{aligned}
$$

respectively, where

$$
\begin{aligned}
\alpha & =\frac{(2+(2 n-3) e)(1-e)}{4+6(n-2) e+\left(2 n^{2}-9(n-1)\right) e^{2}}, \\
\beta & =\frac{(2+(n-2) e)(1+(n-2) e)}{4+6(n-2) e+\left(2 n^{2}-9(n-1)\right) e^{2}}, \\
\gamma & =\frac{e(1+(n-2) e)}{4+6(n-2) e+\left(2 n^{2}-9(n-1)\right) e^{2}}, \\
a & =1-e, \\
b & =1+(n-2) e, \\
f & =\frac{1}{(1+(n-1) e)(1-e)} .
\end{aligned}
$$


Using (15) we find

$q_{i}\left(p_{1}, \ldots, p_{n}\right)=f\left(a+(n-1) e \alpha-b \alpha+((n-1) e \gamma-b \beta) p_{i}+(e \beta+(n-2) e \gamma-b \gamma) \sum_{j \neq i} p_{j}\right)$.

Substituting the values for $\alpha, \beta, \gamma, a, b$ and $f$ we find the input demand function given in $(3)$.

Lemma 5 The competitive benchmark Bertrand-Nash equilibrium values are:

$$
\begin{aligned}
P^{c} & =(1-e) \frac{6+9(n-2) e+\left(3 n^{2}-14 n+14\right) e^{2}}{((n-3) e+2)\left(4+(5 n-11) e+\left(n^{2}-7 n+8\right) e^{2}\right)}, \\
p^{c} & =\frac{\left(2+(4 n-7) e+(2 n-3)(n-2) e^{2}\right)(1-e)}{4+(9 n-19) e+2(3 n-5)(n-3) e^{2}+(n-2)\left(n^{2}-7 n+8\right) e^{3}}, \\
q^{c} & =Q^{c}=\frac{1+(n-2) e}{1+(n-1) e} \frac{2+3(n-2) e+\left(5-5 n+n^{2}\right) e^{2}}{\left(4+(5 n-11) e+\left(8-7 n+n^{2}\right) e^{2}\right)((n-3) e+2)}, \\
\Pi^{c} & =(1-e) \frac{1+(n-2) e}{1+(n-1) e}\left(\frac{\left(2+3(n-2) e+\left(5-5 n+n^{2}\right) e^{2}\right)}{\left(\left(n^{2}-7 n+8\right) e^{2}+(5 n-11) e+4\right)((n-3) e+2)}\right)^{2}, \\
\pi^{c} & =(1-e) \frac{1+(n-2) e}{1+(n-1) e} \frac{(2 n-3) e+2}{(n-3) e+2} \frac{2+3(n-2) e+\left(5-5 n+n^{2}\right) e^{2}}{\left(4+(5 n-11) e+\left(8-7 n+n^{2}\right) e^{2}\right)^{2}} .
\end{aligned}
$$

Proof. Upstream firm $i$ chooses $p_{i}$ such that, given the prices set by the other upstream firms, profits $p_{i}\left(A_{e, n}-B_{e, n} p_{i}+C_{e, n} \sum_{j \neq i} p_{j}\right)$ are maximized. This returns first-order conditions

$$
A_{e, n}-2 B_{e, n} p_{i}+C_{e, n} \sum_{j \neq i} p_{j}=0 .
$$

From these, it follows that the symmetric Bertrand-Nash equilibrium price is

$$
p^{c}=\frac{A_{e, n}}{2 B_{e, n}-(n-1) C_{e, n}} .
$$

Using the definitions of $A_{e, n}, B_{e, n}$ and $C_{e, n}$ given in Lemma 4 , the equilibrium value of $p$, $p^{c}$ in the lemma, follows. Inserting it in equations (2) and (3), the equilibrium values for $P^{c}$ and $q^{c}=Q^{c}$ follow. Finally, downstream firm profits can be found by substituting outputs and prices in $\Pi=(P-p) q$, and likewise upstream firm profits are $\pi=p q$. 


\section{A.3 Upstream Collusion}

Lemma 6 If the upstream industry colludes and maximizes joint profits, it will then set $p^{a}=\frac{1}{2}$. Equilibrium sales will be given by

$$
q^{a}=\frac{1}{2} \frac{1}{1+(n-1) e} \frac{2+(4 n-7) e+(2 n-3)(n-2) e^{2}}{4+6(n-2) e+\left(2 n^{2}-9(n-1)\right) e^{2}}
$$

and each upstream firm will make profit equal to

$$
\pi^{a}=\frac{1}{4} \frac{1}{1+(n-1) e} \frac{2+(4 n-7) e+(2 n-3)(n-2) e^{2}}{4+6(n-2) e+\left(2 n^{2}-9(n-1)\right) e^{2}} .
$$

In best-reply to the upstream cartel, the downstream firms will in Bertrand-Nash equilibrium each set

$$
P^{a}=\frac{6+(8 n-17) e+(2 n-3)(n-4) e^{2}}{8+12(n-2) e+2\left(2 n^{2}-9 n+9\right) e^{2}}
$$

and see their individual firm profits reduced to

$\Pi^{a}=\frac{1}{2} \frac{1}{1+(n-1) e} \frac{2+(2 n-5) e-(2 n-3) e^{2}}{8+12(n-2) e+2\left(2 n^{2}-9 n+9\right) e^{2}} \frac{2+(4 n-7) e+(2 n-3)(n-2) e^{2}}{4+6(n-2) e+\left(2 n^{2}-9(n-1)\right) e^{2}}$.

Proof. The upstream cartel maximizes

$$
\sum_{i=1}^{n} p_{i} q_{i}\left(p_{1}, \ldots, p_{n}\right)=\sum_{i=1}^{n} p_{i}\left(A_{e, n}-B_{e, n} p_{i}+C_{e, n} \sum_{j \neq i} p_{j}\right)
$$

The first-order condition with respect to price $p_{k}$ is

$$
A_{e, n}-2 B_{e, n} p_{k}+2 C_{e, n} \sum_{j \neq k} p_{j}=0 .
$$

Giving that the equilibrium has to be symmetric,

$$
p^{a}=\frac{1}{2} \frac{A_{e, n}}{B_{e, n}-(n-1) C_{e, n}}=\frac{1}{2},
$$

using the expressions for $A_{e, n}, B_{e, n}$ and $C_{e, n}$ determined before in Lemma 4. The output for each individual upstream firm $i$ will then be

$$
q_{i}\left(p_{1}^{a}, \ldots, p_{n}^{a}\right)=A_{e, n}-\left(B_{e, n}-C_{e, n}(n-1)\right) p^{a}=A_{e, n}\left(1-p^{a}\right)=\frac{1}{2} A_{e, n}=q^{a} .
$$

Finally, individual upstream firm profit is going to be

$$
\pi^{a}=p^{a} q^{a}=\frac{1}{4} A_{e, n}
$$


which is equal to the expression given in the lemma. Substituting $p^{a}$ in (2), the values for $P^{a}$ and $\Pi^{a}$ follow straightforwardly.

\section{Proof of Proposition 1.}

As explained in the text, the essential difficulty in showing deterrence is the possibility that damages claims may be let to accumulate rather than being filed. The proof that this is not profitable when back-damages are bounded proceeds in four steps. Step 1 and 2 derive two intermediate results. In Step 3 it is established that any accumulation time is finite. Deterrence of the cartel is then argued in Step 4.

Step 1. Total welfare decreases in the upstream cartel price. To see this, let the uniform cartel price be $p_{1}=\ldots=p_{n}=p$, leading to a uniform consumer price which we denote $P(p) \equiv P(p, \ldots, p)$. By Lemma $3, \frac{\partial P}{\partial p}>0$. Using (14) from Lemma 2, it then follows that

$$
\frac{d T}{d p}=\frac{\partial T}{\partial P} \frac{\partial P}{\partial p}=-\frac{n P}{(1+(n-1) e)} \frac{\partial P}{\partial p}<0 .
$$

Step 2. If consumers and downstream firms always claim and $\mu \geq \mu^{*}$, any upstream cartel is deterred. To see this, note that the cartel will be deterred if

$$
p^{c} Q^{c} \geq \widetilde{\pi}(p)=p \widetilde{Q}(P(p))-\mu\left(P(p)-P^{c}+p-p^{c}\right) \widetilde{Q}(P(p)) .
$$

where $\widetilde{Q}(P(p)) \equiv Q(P(p), \ldots, P(p))$. Since both $P(p)$ and $Q(P(p))$ are linear in $p$, it follows that net cartel profits $\widetilde{\pi}(p)$ are quadratic in $p$. Obviously we restrict attention to $p \geq p^{c}$. In fact, if we denote $P(p)=a_{1}+a_{2} p$ and $\widetilde{Q}(P(p))=b_{1}-b_{2} p$, the exact expressions for the positive parameters $a_{1}, a_{2}, b_{1}$ and $b_{2}$ can be found from Lemmas 3 and 4 , the coefficient for the quadratic term is easily seen to be $b_{2}\left(-1+\mu+\mu a_{2}\right)$. This implies that $\widetilde{\pi}(p)$ is a convex function in $p$ if and only if $-1+\mu+\mu a_{2} \geq 0$ or

$$
\mu \geq \mu^{*} \equiv \frac{1}{1+a_{2}}=\frac{1}{1+\frac{\partial P}{\partial p}} .
$$

Notice that for $p$ large enough, $\widetilde{\pi}(p)$ goes to zero, since demand $\widetilde{Q}(P(p))$ goes to zero for high enough prices. Convexity of $\widetilde{\pi}(p)$ therefore implies that $\widetilde{\pi}(p)$ is maximized at $p=p^{c}$. Hence, the cartel will be deterred for $\mu \geq \mu^{*}$.

The magnitude of the critical damage multiple is determined by $\frac{\partial P}{\partial p}$. From Lemma 3 we find that

$$
\frac{\partial P}{\partial p}=\frac{(1+(n-2) e)(2+(2 n-3) e)}{4+6(n-2) e+\left(2 n^{2}-9(n-1)\right) e^{2}} .
$$

It can easily be verified that $\frac{1}{2} \leq \frac{\partial P}{\partial p} \leq 1$, which implies $\frac{1}{2} \leq \mu^{*} \leq \frac{2}{3}$. Note that the value of $\mu^{*}$ depends on $n$ and $e$. In particular, when the market is more competitive - that is, for high values for $n$ and $e$ - the value of $\mu^{*}$ decreases. The intuition for this is that downstream firms will then pass on more of the damages to the consumers (i.e., $\frac{\partial P}{\partial p}$ increases), thereby 
increasing total damages and decreasing the damage multiple sufficient for cartel deterrence. Also note that $\mu \geq \mu^{*}$ is a sufficient, but not a necessary condition for cartel deterrence.

Step 3. Damages will be claimed in finite time. The reason for this is as follows. When a cartel is formed, consumers and the downstream industry each have to decide when to claim for reparation of their damages. Note that in this perfect legal world, the first to claim will break the cartel and instantaneously unravel all further claims. When faced with anticompetitively raised prices, parties can claim right away, in the first period of the law breaching, or they can 'wait and see', in the meantime accumulating a damages claim that surpasses their true hurt. Assuming the cartel starts in period $t=0$, we will demonstrate that there is a finite time period $T^{*}$ in which the consumers will claim their accumulated damages. This implies that also all downstream firms will claim no later than $T^{*}$, and possibly earlier.

Since indirect utility can be written as $V\left(P_{1}, \ldots, P_{n}, M\right)=\widehat{V}\left(P_{1}, \ldots, P_{n}\right)+M$ (see Lemma 2) we can simply aggregate money (or damages) and indirect utility to study welfare effects. Denote by $\Delta \equiv \mu\left(P(p)-P^{c}\right) n Q(P(p))$ the damages, over one period, that consumers can claim and by $V_{d} \equiv V\left(P^{c}, \ldots, P^{c}, M\right)-V(P(p), \ldots, P(p), M)$ the loss in indirect utility arising from the upstream cartel. If damages $\Delta$ are sufficiently high, consumers may have an incentive to delay claiming. Consider an arbitrary time period $T \geq 0$. Claiming at the end of period $T$ will grant consumers an accumulated damages claim of $\Delta_{T}$, whereas delaying claiming for more period would give them $\Delta_{T+1}-V_{d}$, which should be discounted one period back. Claiming in period $T$ is therefore preferred to claiming in period $T+1$ when

$$
\boldsymbol{\Delta}_{T}>\delta\left[\boldsymbol{\Delta}_{T+1}-V_{d}\right] .
$$

If a statute of limitations applies and $T^{s}$ is finite, then it is easily seen that this condition holds for all $T \geq T^{s}$, since for those $T$ we have $\Delta_{T+1}=\Delta_{T}$ so that there is no incentive to wait. We can therefore restrict attention to cases in which the statute does not apply. In those cases (17) reduces to

$$
\begin{aligned}
\sum_{t=0}^{T} \beta^{T-t} \Delta & >\delta\left[\sum_{t=0}^{T+1} \beta^{T+1-t} \Delta-V_{d}\right] \\
& \Leftrightarrow \delta V_{d}+\frac{1}{1-\beta}\left(\left(1-\beta^{T+1}\right)-\delta\left(1-\beta^{T+2}\right)\right) \Delta>0 .
\end{aligned}
$$

A sufficient condition for this condition to hold is that

$$
\left(1-\beta^{T+1}\right)-\delta\left(1-\beta^{T+2}\right) \geq 0 \Leftrightarrow \frac{1-\beta^{T+1}}{1-\beta^{T+2}} \geq \delta .
$$

Given fixed parameter values $\beta<1$ and $\delta<1$, there always exists a finite $T^{*}$ such that this last inequality holds. Moreover, it is easily checked that for all $T>0$ and all $\beta<1$ we have

$$
\frac{1-\beta^{T+2}}{1-\beta^{T+3}}>\frac{1-\beta^{T+1}}{1-\beta^{T+2}},
$$


which implies that if condition (18) holds for $T=T^{*}$, then it will hold for any $T>T^{*}$. Hence, consumers - and thus all parties with standing to sue - claim no later than in period $T^{*}$.

Step 4. Upstream collusion will now be deterred by the following logic. We are left with two possibilities. If an upstream cartel forms, either it is instantaneously sued, or claims are postponed for a finite number of periods and then brought for (depreciated) accumulated damages. By Step 2, we know that instantaneous action deters the upstream cartel from forming, as long as $\mu>\mu^{*}$. Now consider the possibility of extended claims. According to this scenario, the downstream industry and the consumers 'benefit' from the existence of an upstream cartel in conjunction with the possibilities to claim. However, as shown in Step 1 , because total surplus is lower in each period, and since discount factors are assumed to be common between consumers, down- and upstream firms, it follows that the consumers and the downstream industry can only accumulate a claim at the expense of the upstream industry. As a result, the upstream industry, knowing that it will one day face the claim, will refrain from colluding if all parties have standing to sue.

\section{A.4 Illinois Walls}

Lemma 7 If the rationing scheme $(\bar{p}, \bar{q})$ satisfies

$$
\bar{q} \leq \frac{(1+(n-2) e)}{(2+(n-3) e)(1+(n-1) e)}(1-\bar{p}),
$$

then the Bertrand-Nash equilibrium in the downstream industry invoked by that rationing scheme is characterized by prices

$$
\bar{P}(\bar{q})=1-(1+(n-1) e) \bar{q},
$$

so that output and profit follow as

$$
\bar{Q}(\bar{q})=\bar{q} \text { and } \bar{\Pi}(\bar{p}, \bar{q})=(\bar{P}(\bar{q})-\bar{p}) \bar{q}=(1-(1+(n-1) e) \bar{q}-\bar{p}) \bar{q} .
$$

Proof. The Lagrangian of the constrained downstream profit maximization problem is

$$
L\left(P_{i}, \lambda\right)=\left(P_{i}-\bar{p}\right) Q_{i}\left(P_{1}, \ldots, P_{n}\right)+\lambda\left[\bar{q}-Q_{i}\left(P_{1}, \ldots, P_{n}\right)\right],
$$

leading to first-order conditions

$$
\begin{aligned}
Q_{i}+\left(P_{i}-\bar{p}\right) \frac{\partial Q_{i}}{\partial P_{i}}-\lambda \frac{\partial Q_{i}}{\partial P_{i}} & =0 \\
\lambda\left[\bar{q}-Q_{i}\left(P_{1}, \ldots, P_{n}\right)\right] & =0, \lambda \geq 0 \text { and } \bar{q}-Q_{i}\left(P_{1}, \ldots, P_{n}\right) \geq 0
\end{aligned}
$$


There are two candidates for the optimum: one in which the constraint binds $(\lambda>0)$ and one in which it does not $(\lambda=0)$. First, consider the solution for which $\lambda>0$. In this case, it follows from $Q_{i}\left(P_{1}, \ldots, P_{n}\right)=\bar{q}$ that

$$
P_{i}=\frac{1-e+e \sum_{j \neq i} P_{j}-(1+(n-1) e)(1-e) \bar{q}}{1+(n-2) e} .
$$

Prices in the symmetric quantity restricted Bertrand-Nash equilibrium then are

$$
\bar{P}(\bar{q})=1-(1+(n-1) e) \bar{q},
$$

from which the stated quantity and profit follow straightforwardly, using consumer demand (1).

Next, consider the solution for which $\lambda=0$. In this case, the first-order condition $Q_{i}+\left(P_{i}-\bar{p}\right) \frac{\partial Q_{i}}{\partial P_{i}}=0$ returns

$$
\left(1-e-(1+(n-2) e) P_{i}+e \sum_{j \neq i} P_{j}\right)-(1+(n-2) e)\left(P_{i}-\bar{p}\right)=0 .
$$

Solving for the symmetric Bertrand-Nash equilibrium, we now obtain

$$
P^{*}=\frac{1-e+(1+(n-2) e) \bar{p}}{2+(n-3) e} .
$$

This equilibrium, in which downstream firms choose to purchase less than $\bar{q}$, requires that $P^{*}>\bar{P}$. It does not exist as long as $P^{*} \leq \bar{P}$. Condition (19) assures it does not, so that only the solution corresponding to the binding rationing scheme remains, as long as (19) is satisfied.

Proof of Theorem 1. As observed in the text, the upstream cartel will always choose $\left(\bar{p}^{w}, \bar{q}^{w}\right)$ such that (8) holds with equality, and $\bar{p}^{w} \geq p^{c}$. The proof proceeds in four steps. First the incentive constraint will be used to write $\bar{p}$ as a function of $\bar{q}$. Then, this relation is used to maximize upstream profits. Then the values of $\delta$ for which the optimal value of $\bar{q}$ is (weakly) lower than the Bertrand-Nash quantity $q^{c}$ is established. Finally, we show that for the rationing scheme $\left(\bar{p}^{w}, \bar{q}^{w}\right)$ condition (19) of Lemma 7 holds, so that each retailer will accept the full offer.

Step 1. The binding incentive constraint simplifies to

$$
\frac{\delta}{1-\delta} \bar{\Pi}(\bar{p}, \bar{q})=\varphi D(\bar{p}, \bar{q})+\frac{\delta}{1-\delta} \Pi^{c} .
$$

Note that obviously $\left(p^{c}, q^{c}\right)$ satisfies this constraint, for under regular Bertrand competition, there would be no damages. Hence, the profit maximizing cartel supply of inputs at low prices needs to give weakly higher profits to the cartel than under competition, for otherwise 
the cartel would choose to compete honestly. Using the definition of the overcharge and the specification of $\bar{\Pi}$, the constraint can be written as

$$
\frac{\delta}{1-\delta}[(\bar{P}(\bar{q})-\bar{p}) \bar{q}]-\varphi\left(\bar{p}-p^{c}\right) \bar{q}=\frac{\delta}{1-\delta} \Pi^{c}
$$

so that $\bar{p}$ can be isolated as

$$
\bar{p}=\frac{1}{1+\frac{1-\delta}{\delta} \varphi}\left(\bar{P}(\bar{q})+\frac{1-\delta}{\delta} \varphi p^{c}-\frac{\Pi^{c}}{\bar{q}}\right) .
$$

Step 2. The upstream profits, using this relationship between $\bar{p}$ and $\bar{q}$ along the incentive constraint, now can be written as

$$
\bar{\pi}=\bar{p} \bar{q}=\frac{1}{1+\frac{1-\delta}{\delta} \varphi}\left(\bar{P}(\bar{q}) \bar{q}+\frac{1-\delta}{\delta} \varphi p^{c} \bar{q}-\Pi^{c}\right)
$$

which is maximized at a quantity that satisfies

$$
\frac{\partial \bar{P}(\bar{q})}{\partial \bar{q}} \bar{q}+\bar{P}(\bar{q})+\frac{1-\delta}{\delta} \varphi p^{c}=0 .
$$

Let this quantity be $\bar{q}^{w}$-where 'w' refers to this being the situation under the wall-which depends on $\frac{1-\delta}{\delta} \varphi$ and the downstream price $\bar{P}\left(\bar{q}^{w}\right)$. The associated upstream price is

$$
\bar{p}^{w}=\frac{1}{1+\frac{1-\delta}{\delta} \varphi}\left(\bar{P}\left(\bar{q}^{w}\right)+\frac{1-\delta}{\delta} \varphi p^{c}-\frac{\Pi^{c}}{\bar{q}^{w}}\right) .
$$

Step 3. Now for an Illinois Wall to exist, we need that $\bar{p}^{w}$ is weakly larger than $p^{c}$. That is,

$$
\bar{p}^{w}=\frac{1}{1+\frac{1-\delta}{\delta} \varphi}\left(\bar{P}\left(\bar{q}^{w}\right)+\frac{1-\delta}{\delta} \varphi p^{c}-\frac{\Pi^{c}}{\bar{q}^{w}}\right) \geq p^{c} .
$$

Note that this condition is equivalent with

$$
\bar{P}\left(\bar{q}^{w}\right) \geq P^{c} .
$$

Combining it with first-order condition (20) evaluated at $\bar{q}=q^{c}$, we obtain

$$
\frac{\partial \bar{P}\left(q^{c}\right)}{\partial \bar{q}} q^{c}+P^{c}+\frac{1-\delta}{\delta} \varphi p^{c} \leq 0
$$

which, using the fact that for our specific model we have $\frac{\partial \bar{P}\left(q^{c}\right)}{\partial \bar{q}} q^{c}+P^{c}=2 P^{c}-1$, can be rewritten as

$$
\frac{1-\delta}{\delta} \varphi \leq \frac{1-2 P^{c}}{p^{c}}
$$


It follows that for $\delta>\frac{\varphi p^{c}}{\varphi p^{c}+\left(1-2 P^{c}\right)}, \bar{p}^{w}>p^{c}$ and $\bar{\pi}^{w}>\pi^{c}$. Using the specifications for $P^{c}$ and $p^{c}$ given in Lemma 5 , the following explicit expression for the critical value $\delta^{*}=\delta(n, e, \varphi)$ results:

$$
\begin{aligned}
\delta^{*} & =\frac{\varphi p^{c}}{\varphi p^{c}-\left(\frac{\partial \bar{P}\left(q^{c}\right)}{\partial \bar{q}} q^{c}+P^{c}\right)} \\
& =\frac{\varphi p^{c}}{\varphi p^{c}+\left(1-2 P^{c}\right)} \\
& =\delta(n, e, \varphi)=\frac{\varphi \vartheta(n, e)}{\varphi \vartheta(n, e)+\xi(n, e)},
\end{aligned}
$$

in which

$$
\begin{aligned}
& \vartheta(n, e)=(1-e)((2 n-3) e+2)((n-3) e+2) \text { and } \\
& \xi(n, e)=\left(4+n-4 n^{2}+n^{3}\right) e^{3}+\left(n^{2}+6 n-15\right) e^{2}-2(2 n-7) e-4 .
\end{aligned}
$$

Step 4. Finally, we check that condition (19) holds for the arrangement. That is, we need to show that

$$
\bar{P}^{w} \geq \frac{1-e+(1+(n-2) e) \bar{p}^{w}}{2+(n-3) e},
$$

for all values of $\delta$ and $\varphi$ such that $\frac{1-\delta}{\delta} \varphi \leq \frac{1-2 P^{c}}{p^{c}}$. Note that by construction for $\frac{1-\delta}{\delta} \varphi=$ $\frac{1-2 P^{c}}{p^{c}}$ we have $\bar{P}^{w}=P^{c}, \bar{q}^{w}=q^{c}$ and $\bar{p}^{w}=p^{c}$, so that in that case (19) holds with equality. Using the explicit expressions for $\bar{P}^{w}$ and $\bar{p}^{w}$, condition (21) reduces to

$$
\begin{aligned}
& (2+(n-3) e)\left(\frac{1}{2}-\frac{1}{2} \frac{1-\delta}{\delta} \varphi p^{c}\right) \\
\geq & 1-e+(1+(n-2) e)\left(\frac{1}{2} \frac{1+\frac{1-\delta}{\delta} \varphi p^{c}}{1+\frac{1-\delta}{\delta} \varphi}-\frac{2(1+(n-1) e) \Pi^{c}}{\left(1+\frac{1-\delta}{\delta} \varphi\right)\left(1+\frac{1-\delta}{\delta} \varphi p^{c}\right)}\right) .
\end{aligned}
$$

Defining $a \equiv \frac{1-\delta}{\delta} \varphi$ this last inequality can be rewritten as $f(a) \geq 0$, where

$$
\begin{aligned}
f(a)= & (2+(n-3) e)\left(1-\left(a p^{c}\right)^{2}\right)(1+a)-2(1-e)(1+a)\left(1+a p^{c}\right) \\
& -(1+(n-2) e)\left(\left(1+a p^{c}\right)^{2}-4(1+(n-1) e) \Pi^{c}\right) .
\end{aligned}
$$

Notice that $f(a)$ is a third-degree polynomial in $a$, one root of which is given by $a^{*}=\frac{1-2 P^{c}}{p^{c}}$. Therefore $f(a)$ can be factorized as

$$
f(a)=\left(\frac{1-2 P^{c}}{p^{c}}-a\right)\left(c_{0}+c_{1} a+c_{2} a^{2}\right)
$$

for certain constants $c_{0}, c_{1}$ and $c_{2}$. Non-negativity of these coefficients $c_{0}, c_{1}$ and $c_{2}$ is a sufficient condition for $f(a)$ to be nonnegative for all $a \leq \frac{1-2 P^{c}}{p^{c}}$, which is what we want to 
show. The coefficients $c_{0}, c_{1}$ and $c_{2}$ have to satisfy the following four restrictions:

$$
\begin{aligned}
\frac{1-2 P^{c}}{p^{c}} c_{0} & =(1+(n-2) e)\left(4(1+(n-1) e) \Pi^{c}\right)-(1-e) ; \\
\frac{1-2 P^{c}}{p^{c}} c_{1}-c_{0} & =(n-1) e-2(2+(n-3) e) p^{c} ; \\
\frac{1-2 P^{c}}{p^{c}} c_{2}-c_{1} & =-(3+(2 n-5) e)\left(p^{c}\right)^{2}-2(1-e) p^{c} ; \text { and } \\
-c_{2} & =-(2+(n-3) e)\left(p^{c}\right)^{2} .
\end{aligned}
$$

From the last two restrictions, we obtain that $c_{1}$ and $c_{2}$ are positive. What remains to be shown is that $c_{0} \geq 0$, or equivalently that

$$
(1+(n-2) e)\left(4(1+(n-1) e) \Pi^{c}\right) \geq(1-e) .
$$

Straightforward computations, using the expressions for $P^{c}, p^{c}$ and $\Pi^{c}$ from Lemma 5 , return that this is equivalent to $P^{c} \leq \frac{1}{2}$, which demarcates precisely the case we are restricting attention to. Hence, there will be no unilateral incentive to purchase and produce less than maximum rationed capacity.

\section{References}

[1] Baker, J.B., "Private Information and the Deterrent Effect of Antitrust Damage Remedies," Journal of Law, Economics, and Organization, 4, 1988, 385-408;

[2] Besanko, D. and D.F. Spulber, "Are Treble Damages Neutral? Sequential Equilibrium and Private Antitrust Enforcement," American Economic Review, 80, 1990, 870-887;

[3] Bowley, A.L., The Mathematical Groundwork of Economics, Oxford University Press, Oxford, 1924;

[4] Briggs, H.C., K.D. Huryn and M.E. McBride, "Treble Damages and the Incentive to Sue and Settle," RAND Journal of Economics, 27(4), 1996, 770-786.

[5] Brina, R., "Complexities of Accrual: The Antitrust Stature of Limitations in a Contractual Context," University of California at Los Angeles Law Review, 31, 1984, 1061-1100;

[6] Davis, R.W., "Indirect Purchaser Litigation: ARC America's Chickens Come Home to Roost on the Illinois Brick Wall," Antitrust Law Journal, 65, 1997, $375-406$;

[7] Friedman, J.W., "A Non-cooperative Equilibrium for Supergames," Review of Economic Studies, 38, 1971, 1-12; 
[8] Greenhut, M.L. and H. Ohta, "Vertical Integration of Successive Oligopolists," American Economic Review, 69, 1979, 137-141;

[9] Harris, R.G. and L.A. Sullivan, "Passing on the Monopoly Overcharge: A Comprehensive Policy Analysis," University of Pennsylvania Law Review, 128, 1979, 269-360;

[10] Harrington, J.E., Jr., "Post-Cartel Pricing During Litigation," Journal of Industrial Economics, 52, 2004a, 517-533;

[11] Harrington, J.E., Jr., "Cartel Pricing Dynamics in the Presence of an Antitrust Authority," RAND Journal of Economics, 35, 2004b, 651-673;

[12] Hovenkamp, H., Federal Antitrust Policy: The Law of Competition and Its Practice, Hornbook Series, West Publishing Co., New York, 1999;

[13] Joyce, J.M. and R.H. McGuckin, "Assignment of Rights to Sue under Illinois Brick: An Empirical Assessment," Antitrust Bulletin, 31(1), 1986, 235-259;

[14] Kolasky, W.J., "Coordinated Effects in Merger Review: From Dead Frenchmen to Beautiful Minds and Mavericks," address before the American Bar Association, April 24, 2002;

[15] Lande, R.H., "Are Antitrust 'Treble' Damages Really Single Damages?," Ohio State Law Journal, 54, 1993, 115-174;

[16] Landes, W.M. and R.A. Posner, "Should Indirect Purchasers have Standing to Sue under the Antitrust Laws? An Economic Analysis of the Rule of Illinois Brick," University of Chicago Law Review, 46, 1979, 602-635;

[17] Landes, W.M. and R.A. Posner, "The Economics of Passing On: A Reply to Harris and Sullivan," University of Pennsylvania Law Review, 128, 1980, 12741279 ;

[18] Levenstein, M.C. and V.Y. Suslow, "What Determines Cartel Success?" forthcoming in Journal of Economic Literature, manuscript, January 2004;

[19] Lopatka, J.E. and Page, W.H., "Indirect Purchaser Suits and the Consumer Interest," Antitrust Bulletin, 48, 2004, 531-570;

[20] Lovell, M.C., "Are Treble Damages Double Damages?," Journal of Economics and Business, 34, 1982, 263-268;

[21] McCutcheon, B., "Do Meetings in Smoke-Filled Rooms Facilitate Collusion?," Journal of Political Economy, 105, 1997, 330-350; 
[22] Page, W.H. (ed.), Proving Antitrust Damages: Legal and Economic Issues, American Bar Association, Chicago, 1996;

[23] Page, W.H., "The Limits of State Indirect Purchaser Suits: Class Certification in the Shadow of Illinois Brick," Antitrust Law Journal, 67, 1999, 1-40;

[24] Salant, S.W., "Treble Damage Awards in Private Lawsuits for Price Fixing," Journal of Political Economy, 95, 1987, 1326-1336;

[25] Salop, S.C. and L.J. White, "Economic Analysis of Private Antitrust Litigation," Georgetown Law Journal, 74, 1986;

[26] Scherer, F.M., "How US Antitrust Can Go Astray: The Brand Name Prescription Drug Litigation," International Journal of the Economics of Business, 4(3), 1997, 239-256;

[27] Schinkel, M.P., J. Tuinstra and J. Rüggeberg, "Illinois Walls," CeNDEF Working Papers Series 04/03, 2004;

[28] Schinkel, M.P. and J. Tuinstra, "Illinois Walls in Alternative Markets Structures," CeNDEF Working Paper Series 05/11, 2005;

[29] Sneeden, E.M., "Illinois Brick-Do We Look to the Courts or Congress," Antitrust Bulletin, 24, 1979, 205-231;

[30] Snyder, E.A., "Efficient Assignment of Rights to Sue for Antitrust Damages," Journal of Law \&3 Economics, 28, 1986, 469-482;

[31] Spengler, J.J., "Vertical Integration and Antitrust Policy," Journal of Political Economy, 58, 1950, 347-352;

[32] Vives, X., Oligopoly Pricing: Old Ideas and New Tools, MIT Press, Cambridge, MA, 1999;

[33] Wils, W.P.J., "Should Private Antitrust Enforcement Be Encouraged in Europe?," World Competition, 26, 2003, 473-488. 